\title{
Risk premiums and macroeconomic dynamics in a heterogeneous agent model
}

\author{
Ferre De Graeve ${ }^{\mathrm{a}, *}$, Maarten Dossche ${ }^{\mathrm{b}}$, Marina Emiris ${ }^{\mathrm{c}}$, Henri Sneessens ${ }^{\mathrm{d}, \mathrm{e}, \mathrm{f}}$, Raf Wouters ${ }^{\mathrm{b}}$ \\ ${ }^{a}$ Research Department, Sveriges Riksbank, SE 10337 Stockholm, Sweden \\ ${ }^{\mathrm{b}}$ National Bank of Belgium, Belgium \\ c Bank of Canada, Canada \\ ' CREA, Université du Luxembourg, Luxembourg \\ e IRES, Université catholique de Louvain, Belgium \\ f IZA, Germany
}

\section{A R T I C L E I N F O}

Available online 23 June 2010

\section{JEL classification:}

E32

E44

G12

Keywords:

Equity Premium

Bond Premium

Limited participation

DSGE

\begin{abstract}
A B S T R A C T
We analyze financial risk premiums and real economic dynamics in a DSGE model with three types of agents-shareholders, bondholders and workers-that differ in participation in the capital market and in attitude towards risk and intertemporal substitution. Aggregate productivity and distribution risks are transferred across these agents via the bond market and via an efficient labor contract. The result is a combination of volatile returns to capital and a highly cyclical consumption process for the shareholders, which are two important ingredients for generating high and countercyclical risk premiums. These risk premiums are consistent with a strong propagation mechanism through an elastic supply of labor, rigid real wages and a countercyclical labor share. Based on the empirical estimates for the two sources of real macroeconomic risk, the model generates significant and plausible time variation in both bond and equity risk premiums. Interestingly, the single largest jump in both the risk premium and the price of risk is observed during the current recession.
\end{abstract}

(c) 2010 Elsevier B.V. All rights reserved.

\section{Introduction}

Economic models typically have a hard time reproducing the observed risk premiums and real statistics simultaneously. The need for such a consistent model is high. For instance, it would make it possible to extract the information contained in asset prices about future growth and inflation expectations of private investors by controlling for the implied risk premiums. At the same time, a model that can jointly match financial and real statistics would have strong empirical validity. The standard DSGE model with endogenous capital and labor has problems generating sufficiently large premiums and realistic real statistics because investors have various channels through which they can smooth consumption. Various solutions have been suggested in the literature to overcome this problem within the standard representative agent model. Recent examples include, among others, Lettau and Uhlig (2000) who evaluate the potential role of habit formation, Boldrin et al. (2001) suggest frictions in the labor allocation between sectors, Uhlig (2007) proposes real wage rigidity as a possible solution.

\footnotetext{
* Corresponding author.

E-mail address: ferre.de.graeve@riksbank.se (F. De Graeve).
} 
In this paper, we follow Guvenen (2009), Danthine and Donaldson (2002) and Danthine et al. (2008), and focus on the role of heterogeneous capital market participation across agents. This setup implies a number of interesting features that can facilitate the joint explanation of real and financial statistics. First, in such a setup, it is no longer aggregate consumption that drives the pricing kernel of asset prices. There is a well documented literature that suggests that the consumption of wealthy agents, that hold the majority of the capital stock, is more volatile than aggregate consumption. Second, in a context of heterogeneous agents, the valuation of the capital stock is not only determined by aggregate risk, but also by distribution risk. The volatile and highly procyclical nature of profits can potentially contribute significantly to the explanation of the equity risk premium. Importantly, it can help to differentiate between stock and bond risk premiums. The risk sharing between heterogeneous agents does not only affect the pricing of the claims on future profits but also offers the natural context to explain the observed acyclical behavior of real wages and the countercyclical behavior of the wage share. Third, an explanation of the risk premium based on heterogeneous capital market participation across agents has important empirical implications for the financial behavior of the different agents, for instance in terms of wealth accumulation and the resulting wealth distribution. Therefore, this approach has the advantage that the underlying assumptions can be validated more easily compared to alternative explanations which are often based on non-observable features of the utility functions (another popular solution to the equity premium in the context of a representative agent model).

We integrate the models of Danthine, Donaldson and Guvenen in a general framework in which all agents participate in the labor market and have similar preferences, but with heterogeneous attitudes towards risk and intertemporal substitution and with varying degrees of capital market access. The model contains three types of agents: workers, who do not participate in the capital market, bondholders and shareholders. Workers and shareholders will exchange their income risk through a labor contract as proposed in Danthine and Donaldson. Bondholders and shareholders will share their risk through the bond market, as in Guvenen. As a first contribution, we show that this model, driven by a combination of aggregate productivity and distribution shocks, is able to generate significant risk premiums as well as realistic aggregate volatilities and correlations. In particular, the optimal labor contract, motivated by risk sharing considerations, explains the observed rigidity and low volatility in the real wage, as well as the countercyclical wage share. The optimal wage contract and the stochastic distribution risk-which takes up possible shifts in the relative bargaining power of workers and firms - deliver a high volatility in profits, returns to equity and price-dividend ratios. This high volatility in the returns from capital, combined with the high concentration of capital market participation, results in a concentration of risk and a consequently high consumption volatility for the shareholders. The bond trade between bond- and shareholders contributes only marginally to our results. In the face of distribution risk, shareholders are reluctant to bear additional aggregate risk through the bond trade. This result suggests important interactions between the two risk sharing devices in a general setup.

By integrating the two risk sharing mechanisms in a common framework, the specific features of each mechanism and their dependence on specific assumptions become more apparent. Furthermore, we evaluate the performance of the model by studying their implications for both bond and equity returns. This focus on a variety of assets (bonds, as well as stocks) imposes additional discipline in building the model. For one, reproducing observed differences in returns to stocks and bonds has implications for the degree of flexibility one has in modeling the agents' stochastic discount factor. Moreover, the macroeconomic fluctuations that underlie the various risk premiums are model-consistent. Put differently, the general equilibrium framework adopted ensures a joint explanation, without relying on, e.g., reduced form macroeconomic dynamics to mimic risk premiums.

The third contribution of the paper is applied in nature. We estimate the stochastic structure of the model based on real US data over the period 1947q1-2009q1. The resulting series for the productivity and distribution shocks are fed into model. Based on these two real sources of macroeconomic risk, the model generates significant and plausible time variation in the financial premiums. Taking into account the limited stochastic structure of this exercise, the resulting time variation in risk premiums compares well to available proxies and estimates in the literature. The risk premiums display a strong increase during each of the postwar recession periods. In particular, the single largest jump in both the risk premium and the price of risk is observed during the current recession. We also perform predictive regressions for stocks and bonds to further measure the success and limitations of the model.

In Section 2, we present the model and the estimation results for its stochastic structure. Section 3 documents the main financial and real statistics implied by the model, and compares them with analog statistics in the data and implied statistics of the representative agent version of the model. The specific role of the two risk sharing mechanisms is analyzed in detail. In Section 4, we perform a sensitivity exercise to illustrate the role of the stochastic structure, the structural parameters, the specification of the utility function, and the heterogeneity across agents. The difference between the equity and bond premium is discussed in Section 5. Finally, Section 6 presents the results on the implied time variation in the risk premiums, and shows how this variation affects the predictive power of the price-dividend ratio and the yield spread. Our analysis is based on simulation experiments with the first, second and third order approximation of the non-linear model using the Dynare and Dynare+t toolbox.

\section{The model}

We start from a general setup which considers three types of agents. A first group of agents consists of the standard portfolio investors that allocate their wealth between stocks and bonds. These agents act as the marginal investors that clear the bond and stock markets. Therefore, their stochastic discount factor will determine the pricing of the corresponding risks. 
Motivated by empirical evidence, we assume that the portfolio managers are characterized by a lower risk aversion than the other agents in the economy. We refer to these agents as shareholders (type 1 agents, T1). A second group of agents, bondholders (T2), participates in the capital market by buying bonds. Their bondholdings depend on their desire to smooth consumption as well as their precautionary savings, and determine the wealth accumulation of these agents. Finally, a third group of agents, workers (T3), does not participate in the capital market and consumes immediately its income from labor. In order to smooth their marginal utility, these agents are completely dependent on the labor contract which provides the only opportunity for them to share their income risk with the other agents in the economy, in particular with the shareholders as owners of the firms. In a context of continued labor-firm relations, the optimal labor contract guarantees an exogenously determined ratio between the marginal utility of the workers and the marginal utility of the shareholder of the firms. More risk averse types 2 and 3 agents will try to transfer some of the aggregate risk towards the shareholders, either via savings in the bond market or via the wage contract. In exchange the shareholders will require a higher return.

This general setting allows us to review specific cases that have been considered previously in the literature. When the economy is vacated by shareholders alone, the model is very similar to the standard representative agent model, analyzed in, e.g., Uhlig (2007). This makes it easy to compare the outcomes of the general model with the representative agent version, and to review the implications of the various model assumptions within a more standard setup. The sensitivity of the outcomes to the various model features will be discussed extensively in the next section.

Alternatively, when more than one type of household is present, the model encompasses a variety of asset pricing models with heterogeneous agents. For instance, when both shareholders and bondholders are present, our model is similar to that of Guvenen (2009). Alternatively, when the economy consists of shareholders as well as workers, our setup is very close to that of Danthine and Donaldson (2002). With all three agents present, our model has the flavor of agent heterogeneity as analyzed in Chien et al. (2010). In our production economy, we incorporate the labor decision for shareholders and bondholders in all versions to maintain comparability over different models. Excluding the labor choice for these agents would make it easier to fit the asset pricing moments, as the labor choice offers shareholders another channel to smooth fluctuations in marginal utility.

\subsection{Households}

There are three different types of households in our model economy: shareholders, bondholders and workers. The types of households differ in the way they participate in the financial market, in the way they insure against macroeconomic risk and in their preferences toward risk and intertemporal substitution. All agents maximize expected utility, which depends positively on consumption and negatively on the amount of labor supplied.

\subsubsection{Type 1 agents: shareholders}

Shareholders are able to invest both in stocks and bonds. They choose the amount of working hours $\left(N_{1, t}\right)$ they supply at the prevailing spot market wage rate $\left(W_{t}^{S}\right)$. The decision problem for these shareholders is thus:

$$
\begin{aligned}
& \max \quad E_{t} \sum_{j=0}^{\infty} \beta^{t} U_{1}\left(C_{1, t+j}, N_{1, t+j}\right) \\
& \text { s.t. } \quad C_{1, t}+P_{t}^{B} B_{1, t+1}+P_{t}^{S} S_{1, t+1} \leq B_{1, t}+S_{1, t}\left(P_{t}^{S}+D_{t}\right)+W_{t}^{s} N_{1, t}+\Gamma_{t}
\end{aligned}
$$

In words, the shareholders' budget constraint states that their expenditures on consumption $\left(C_{1, t}\right)$, bonds $\left(B_{1, t+1}\right)$ and stocks $\left(S_{1, t+1}\right)$, cannot exceed total income. Bonds are sold at a price $P_{t}^{B}$, while shares trade at price $P_{t}^{S}$. In addition to labor income $\left(W_{t}^{s} N_{1, t}\right)$, shareholders obtain funds from previous bond holdings $\left(B_{1, t}\right)$, from stock holdings $\left(S_{1, t} P_{t}^{S}\right)$ and through dividend payments by the firms $\left(S_{1, t} D_{t}\right)$ and the financial intermediary $\left(\Gamma_{t}\right.$, see below). This maximization problem results in the standard FOC. In particular, they mimic the well known conditions for consumption, labor and asset holdings in a standard representative agent model. The stochastic discount factor of the shareholders is also used to price long term real bonds. ${ }^{1}$

\subsubsection{Type 2 agents: bondholders}

Bondholders do not hold any shares in their portfolio. Bondholders also differ from shareholders in that their momentary utility function is characterized by a higher degree of risk aversion, but they are otherwise very similar. In particular, the type 2 agents also work at the spot wage and thus maximize:

$$
\begin{aligned}
& \max \quad E_{t} \sum_{j=0}^{\infty} \beta^{t} U_{2}\left(C_{2, t+j}, N_{2, t+j}\right) \\
& \text { s.t. } \quad C_{2, t}+\frac{P_{t}^{B} B_{2, t+1}}{\Phi\left(B_{2, t+1}\right)} \leq B_{2, t}+W_{t}^{s} N_{2, t}
\end{aligned}
$$

\footnotetext{
${ }^{1}$ We consider decaying coupon perpetuities as in Rudebusch and Swanson (2008).
} 
Bondholders engage in bond accumulation via a financial intermediary. In doing so, they are subject to a portfolio cost $\Phi\left(B_{2, t+1}\right)$. We introduce such a cost for bond holdings so that the return on bonds will depend on the macro bond supply. The more bondholders save, the lower the return. The more debt they accumulate, the higher the cost. This cost is taken as given from the point of view of an individual bondholder. This mechanism is the same as in Benigno (2009) who uses it in a two-country model. The introduction of such an intermediation margin is necessary to avoid infinite bond holdings or borrowing. This assumption has very similar consequences as the discrete constraints on bond positions as imposed in, e.g., Guvenen (2009). The latter setup cannot be used when applying perturbation methods to solve the model, as we do below. For sufficiently small values of the elasticity of the bond price to the overall bond holdings, this bond holding cost has a negligible effect on the savings decisions of bondholders and on the risk premiums in the model. ${ }^{2}$ The intermediation profits made by the financial intermediary $\Gamma_{t}$ are rebated to the shareholders.

\subsubsection{Type 3 agents: workers}

The third type of agents also derive utility from consumption and labor, with felicity function $U_{3}($.$) :$

$$
\begin{aligned}
& \max E_{t} \sum_{j=0}^{\infty} \beta^{t} U_{3}\left(C_{3, t+j}, N_{3, t+j}\right) \\
& C_{3, t}=W_{t}^{c} N_{3, t}
\end{aligned}
$$

The main difference from the other types of agents is that workers do not participate in financial markets at all and cannot accumulate wealth. As a result, these agents consume their entire labor income each period. We assume that workers engage in long-term labor contracts with the firms. ${ }^{3,4}$ The workers earn a contract wage $\left(W_{t}^{c}\right)$. In exchange they deliver the efficient labor input to the firms. The wage contract solves:

$$
\max E_{t}\left\{\varpi_{t} U_{1}\left(C_{1, t}, N_{1, t}\right)+\left(1-\varpi_{t}\right) U_{3}\left(C_{3, t}, N_{3, t}\right)\right\}
$$

where $\varpi_{t}$ measures the bargaining weight of the shareholder, and the optimization is subject to the budget constraint of the workers and the shareholders. The contract is summarized by the following two conditions:

$$
\begin{aligned}
& U_{1, t}^{C}=v_{t} U_{3, t}^{C} \quad \text { with } v_{t}=\frac{\left(1-\varpi_{t}\right)}{\varpi_{t}} \\
& W_{t}^{s}=-\frac{U_{3, t}^{N}}{U_{3, t}^{C}}
\end{aligned}
$$

In the first condition the ratio between the two marginal utilities reflects the relative bargaining power of the two parties in the contract arrangement. The shareholders guarantee a consumption level to the workers that implies a constant relative marginal utility. The contract wage thus guarantees an optimal risk sharing between workers and shareholders on a period-by-period basis for a given realization of the exogenous bargaining weight $v_{t}$. With a fixed value of $v$, the contract provides optimal insurance against aggregate risk and reproduces the same outcome as the exchange of contingent securities (constant relative marginal utilities), at given wealth distribution. ${ }^{5}$ This setup is also considered in Danthine and Donaldson (2002) who assume, however, that labor supply is exogenous. Relative to the outcome under a spot labor market, the contract wage contains an insurance premium through which workers exchange risk with the marginal shareholder of the firms. Given the high risk aversion (or low IES) of the workers, the contract wage guarantees them a smooth consumption stream.

Descriptive realism aside (see Danthine and Donaldson, 2002 for more on this), the wage contract has implications consistent with macro-financial data. Given workers' demand for smooth consumption, the contract wage will be fairly stable. Real wage stickiness, by itself, is consistent with macro data, and can also help in generating financial risk premiums, as documented by Uhlig (2007). Here, the contract generates a countercyclical labor share and more volatile and highly procyclical profits, which will help in generating risk premiums.

The efficient contract wage has only distributive effects, and does not create any allocative distortion. In exchange for the insurance provided by the firm, workers offer the required labor services to the firm. This means that workers will

\footnotetext{
${ }^{2}$ The bond portfolio cost, in fact, generally does not have a significant impact on the risk premium statistics reported below. In principle, the introduction of the borrowing cost can generate a (first order) term premium of its own, from the bondholder perspective. Throughout, all reported financial prices are based on the shareholder stochastic discount factor. As an indication of how small the calibrated borrowing cost is in that regard, in a first order approximation to the model for our baseline calibration the term premium is essentially zero, as it never exceeds $3 \times 10^{-10}$.

${ }^{3}$ See Gomme and Greenwood (1995) and Boldrin and Horvath (1995) for a detailed discussion of labor contracts between workers and entrepreneurs in an RBC model. We have experimented with alternative contract setups. The implications for the labor supply are very similar. To save space we do not report these results in the paper.

${ }^{4}$ An alternative assumption to the permanent relations is that the worker-firm relation takes the form of a one-period contract: this contract will guarantee an expected relative marginal utility level to the workers. If workers have no bargaining power, then this expected relative utility will be equal to the expected outcome in the spot market. If workers have some bargaining power the wage will guarantee something extra relative to the market outcome. This contract setup is similar to the one considered in Boldrin and Horvath (1995).

${ }^{5}$ In particular, the contract then ensures $U_{1, t}^{C} / U_{3, t}^{C}=U_{1, t+1}^{C} / U_{3, t+1}^{C}=(1-\varpi) / \varpi$.
} 
supply labor up to the point where their marginal rate of substitution between labor and consumption is equal to the spot wage, the second condition in (8). ${ }^{6}$

Finally, following Danthine and Donaldson (2002), we consider $v$ to be a time-varying process, driven by exogenous shocks to the bargaining power. We will refer to these shocks as distribution risk where:

$$
\log \left(v_{t}\right)=\left(1-\rho_{v}\right) \log (\bar{v})+\rho_{v} \log \left(v_{t-1}\right)+\varepsilon_{t}^{v}
$$

\subsubsection{Utility function}

In the baseline version of the model, we use the Greenwood, Hercowitz, and Huffman (1988, henceforth GHH) utility specification for all three agents:

$$
G H H: U_{i}\left(C_{i, t}, N_{i, t}\right)=\frac{\left(C_{i, t}-\psi_{i} N_{i, t}^{\phi}\right)^{1-\sigma_{i}}}{1-\sigma_{i}}
$$

We assume that $\sigma_{i}$, which we will refer to as the risk aversion with respect to consumption, differs between shareholders and the two other types of agents. The agents that participate freely in the financial market are assumed to be less risk averse. Our utility function imposes the exact inverse relation between the risk aversion and the intertemporal elasticity of substitution (IES): shareholders are assumed to be characterized by a higher IES. This assumption is in line with the empirical evidence on heterogeneity across different agents (e.g., Vissing-Jørgensen, 2002).

\subsection{Firms}

Firms maximize the present value of the dividend stream using the shareholders' stochastic discount factor:

$$
\max E_{t}\left[\sum_{j=0}^{\infty} \beta^{j} \frac{\lambda_{t+j}}{\lambda_{t}} D_{t+j}(i)\right]
$$

with

$$
D_{t}(i)=\left[Y_{t}(i)-W_{t}^{S} N_{1, t}(i)-W_{t}^{S} N_{2, t}(i)-W_{t}^{c} N_{3, t}(i)-I_{t}(i)+\left(P_{t}^{B_{f}} B_{f, t}(i)-B_{f, t-1}(i)\right)\right]
$$

subject to

$$
\begin{aligned}
& Y_{t}(i)=Z_{t} K_{t}(i)^{\theta} N_{t}(i)^{(1-\theta)} \\
& K_{t+1}(i)=(1-\delta) K_{t}(i)+G\left(\frac{I_{t}(i)}{K_{t}(i)}\right) K_{t}(i) \\
& N_{t}(i)=N_{1, t}(i)+N_{2, t}(i)+N_{3, t}(i)
\end{aligned}
$$

Firms operate in competitive product markets and are identical, such that we can ignore the index $i$. Dividends are defined as total income minus the wage bill (spot wage plus insurance component), minus investment expenditures and plus the net receipts from debt financing. Note that the insurance the firms provide to the workers does not affect the allocation decisions of the firm. Firms thus take a static labor demand decision for the remaining labor inputs which are hired at the spot labor market, and an intertemporal investment decision. Firms use a standard Cobb-Douglas production function, and have a one period financial debt which is a constant fraction of the steady state capital stock $\left(B_{f, t}=\mu K_{s s}\right){ }^{7}$ Finally, the adjustment costs for capital are formulated as

$$
G=a_{1}\left(\frac{I}{K}\right)^{(1-1 / \xi)}+a_{2}
$$

Firms are affected by standard aggregate productivity shocks $Z_{t}$, where

$$
\log \left(Z_{t}\right)=\left(1-\rho_{z}\right) \log (\bar{Z})+\rho_{z} \log \left(Z_{t-1}\right)+\varepsilon_{t}^{z}
$$

The innovations to the productivity process and the distribution process are allowed to be correlated as discussed in the estimation of the model below.

\footnotetext{
${ }^{6}$ In our steady state, we assume that the optimal contract implies a wage and consumption level for the workers that is equivalent to the steady state outcome under the spot labor market. Alternatively, one could also assume that workers have some extra bargaining power, which would result in a consumption level above the spot market outcome. This would imply a lower level of dividends and consumption for the shareholders and at the same time a higher volatility in their dividends/consumption stream (implying a higher risk premium).

${ }^{7}$ We retain a role for financial leverage, as it is introduced by Guvenen (2009) as well as Danthine and Donaldson (2002).
} 
Table 1

Calibration of the parameters.

\begin{tabular}{llllllllll}
\hline$\beta$ & $\delta$ & $\theta$ & $\xi$ & $\Phi_{B}^{\prime}$ & $\mu$ & $\sigma_{1}$ & $\sigma_{2}$ & $\sigma_{3}$ & $\phi$ \\
\hline 0.99 & 0.025 & 0.30 & 0.5 & $5 \times 10^{-5}$ & 0.3 & 4 & 10 & 10 & 1.75 \\
\hline
\end{tabular}

\subsection{Equilibrium}

The production by the firms is equal to aggregate demand. Given that there is no government debt in our model, the bond positions of bond and shareholders must add up to the debt issued by the firms. All debt is in the form of one period discount bonds. Long term bonds are in zero net supply, and the stochastic discount factor of the shareholders is used to price these bonds. In equilibrium the shareholders will own the entire net present value of the firm $P_{t}^{s}$. Therefore, $S_{t}$, the share of the firm that the shareholders own, must be equal to 1 in equilibrium. A final equilibrium condition is that labor markets clear. Thus:

$$
\begin{aligned}
& Y_{t}=C_{1, t}+C_{2, t}+C_{3, t}+I_{t} \\
& B_{1, t}+B_{2, t}=B_{f, t} \\
& S_{1 t}=S_{t}=1 \\
& N_{1, t}+N_{2, t}+N_{3, t}=N_{t}
\end{aligned}
$$

\subsection{Baseline parameterization}

We use the parameter values in Table 1 for the baseline model. The discount factor $(\beta)$ is set at 0.99 . The depreciation rate $(\delta)$ is $2.5 \%$ per quarter. The capital adjustment costs are a function of the change in the capital stock with an elasticity $(\xi)$ set at 0.50 . The parameter in the Cobb-Douglas production function $(\theta)$ is equal to 0.30 . The values for these parameters are standard in the literature. The financial intermediation costs that bondholders face are a linear function of their bondholdings with a small sensitivity of 0.00005 . This guarantees that the effective interest rate that bondholders face will never deviate more than $12.5 \%$ from the market interest rate in the baseline model. This parameter also generates a realistic wealth distribution in the baseline model. Firm debt is assumed to be $30 \%$ of the capital stock.

More important for our application are the functional form and the parameters of the utility function. Under the baseline specification with GHH preferences, we assume a risk aversion with respect to consumption $(\sigma)$ of 10 for the workers and the bondholders, and 4 for the shareholders. Within a standard expected utility context, these values imply an intertemporal elasticity of substitution (IES) of, respectively, 0.1 and 0.25 . The Frisch elasticity of labor supply with respect to wages is assumed to be equal to 1.33 for all agents $(\phi=1.75)$, and $\psi$ is chosen so that hours worked for all agents is the same and scaled at 1 .

The shares of the different agent classes in total population are fixed so that workers make up $60 \%$, bondholders $30 \%$ and shareholders $10 \%$ of the total population. The fraction of the workers reflects the share of the population which is engaged in a labor contract with the firms. The remaining $40 \%$ can be thought of as the self-employed or entrepreneurs who do not benefit from a standard labor contract, but earn a spot wage that reflects their marginal productivity.

\subsection{Estimation of the stochastic structure}

Given these structural parameters, we estimate the stochastic processes for aggregate productivity and distribution risk implied by the model (see Eqs. (9) and (17)). The estimation is based on US data for GDP, consumption, investment, real wages (all expressed per capita) and hours worked over the period 1947q3-2009q1. ${ }^{8}$ We use the log difference of the data (not for hours) as observables and estimate a common deterministic growth rate for these four series. As we use five data series and identify only two structural shocks, we also allow for i.i.d. measurement errors on the five observed variables. The model is estimated using a full information Bayesian estimation methodology. All parameters are estimated with a narrow posterior distribution interval. Table 2 summarizes the results for the parameters of the stochastic processes. These values correspond to the mode of the posterior distribution. ${ }^{9}$

The results for the productivity process are standard with a first order autocorrelation of 0.944 and a standard deviation for $\varepsilon_{t}^{z}$ of $0.64 \%$. The distribution process, that determines the bargaining power of workers and firms in the contract wage, has a higher persistence (0.987) and a standard deviation for $\varepsilon_{t}^{v}$ of $2.53 \%$. The data strongly prefer a negative correlation $(-0.54)$ between these two innovations. Our interpretation for this correlation is that productivity shocks have a significant effect on the distribution of

\footnotetext{
${ }^{8}$ Estimation of both the structural parameters and the stochastic shocks requires a more complete specification of the model, including additional nominal and real frictions and a complete set of structural shocks. Such an exercise is beyond the scope of this paper.

${ }^{9}$ More detailed estimation results are reported in the working paper version, De Graeve et al. (2010).
} 
Table 2

Estimated parameters for the stochastic structure.

\begin{tabular}{llll}
\hline$\sigma_{z}$ & $\rho_{z}$ & $\sigma_{v}$ & $\rho_{v}$ \\
\hline 0.0064 & 0.944 & 0.0253 & 0.987 \\
\hline
\end{tabular}

Table 3

Financial statistics.

\begin{tabular}{|c|c|c|c|c|c|c|c|c|c|c|}
\hline & $S R$ & $E P$ & $B P$ & $y^{40}-\mathrm{R}^{f}$ & $R^{f}$ & $\sigma_{R^{f}}$ & $\sigma_{R^{s}}$ & $\sigma_{C 1}$ & $\sigma_{C 2}$ & $\sigma_{\mathrm{C} 3}$ \\
\hline \multicolumn{11}{|l|}{ Data } \\
\hline $1947-2007$ & 0.39 & 6.11 & $1.06^{*}$ & 1.34 & 1.19 & 2.84 & 15.50 & - & - & - \\
\hline 1926-2007 & 0.26 & 5.85 & $1.76^{* *}$ & - & 0.60 & 5.27 & 22.35 & - & - & - \\
\hline \multicolumn{11}{|l|}{ Models } \\
\hline $\mathrm{T} 1+\mathrm{T} 2+\mathrm{T} 3$ & 0.24 & 5.18 & 2.34 & 1.81 & 1.26 & 1.98 & 22.18 & 3.23 & 1.66 & 1.28 \\
\hline $\mathrm{T} 1+\mathrm{T} 3\left(\varepsilon^{z}, \varepsilon^{v}, \rho\right)$ & 0.26 & 6.72 & 2.83 & 2.24 & 0.50 & 2.09 & 25.43 & 3.31 & - & 1.24 \\
\hline $\mathrm{T} 1+\mathrm{T} 3\left(\varepsilon^{z}, \varepsilon^{v}\right)$ & 0.22 & 4.41 & 1.79 & 1.39 & 1.69 & 1.80 & 20.55 & 3.66 & - & 1.83 \\
\hline $\mathrm{T} 1+\mathrm{T} 3\left(\varepsilon^{z}\right)$ & 0.12 & 1.64 & 0.90 & 0.61 & 3.29 & 1.51 & 13.45 & 1.90 & - & 1.32 \\
\hline $\mathrm{T} 1+\mathrm{T} 2$ & 0.09 & 1.03 & 0.66 & 0.37 & 3.64 & 1.51 & 11.47 & 1.56 & 1.46 & - \\
\hline $\mathrm{T} 1$ & 0.09 & 0.87 & 0.54 & 0.34 & 3.63 & 1.23 & 9.64 & 1.61 & - & - \\
\hline
\end{tabular}

Note: For the period 1926:1-1998:4 we use the dataset of Campbell (2003). For the period 1999:1-2007:4 we use the United States MSCI from Datastream to calculate the equity statistics. To calculate the bond statistics we use the FED Funds rate and the ten year bond from the BIS. The standard deviation of the annualized interest and inflation rate is computed as 400 times the quarterly model concept. The standard deviation of the equity return is computed as that of a compounded annual return. The standard deviation of the annualized equity return is 200 times the quarterly model concept. and ${ }^{* *}$ refer to mean term premium and holding period return over the period 1961-2007, and are taken from Rudebusch and Swanson (2009, Table 2 ).

income: in particular the labor share in total output drops systematically, and according to the estimates also in a very persistent way, following a positive productivity shock. This result is in line with the general finding that wages are highly rigid either in nominal or in real terms. This is also consistent with the drop in the wage share or the real marginal cost after a positive productivity shock..$^{10}$ Usually, this wage rigidity is introduced in the models by some ad hoc assumption on the stickiness of wages or some multi-period wage contract. In our model, the wage rigidity is the outcome of an efficient labor contract between workers and the firms (or their shareholders). As pointed out in Danthine and Donaldson and discussed later on, this correlation between the two sources of risk is important for the risk premium.

The two structural shocks explain a high fraction of the overall volatility in the observed variables (ranging between $60 \%$ and $80 \%$ for the growth rates). As we do not explain $100 \%$ of the volatility, we will rescale the standard deviations of the two innovations upward with $25 \%$ when calculating the risk premiums implied by the model. Without such rescaling, the model would logically underestimate the risk premium as we capture only part of the risk in the economy. This approach assumes that the two structural shocks, that are explicitly considered in the model, are representative for the other unobserved shocks in the economy in terms of their contribution to the risk premium. ${ }^{11}$

\section{Model results}

We discuss the overall statistics of the model both for the real and the financial side of the economy and we compare these results to the data statistics. Next, we turn to the analysis of the risk sharing arrangements in the model.

\subsection{Overall statistics of the model}

Tables 3 and 4 summarize the overall statistics of the baseline three-agent model $(\mathrm{T} 1+\mathrm{T} 2+\mathrm{T} 3)$. One should not expect the model to fit the data moments exactly: in reality more shocks are present and additional nominal and real frictions will affect the transmission of the shocks. The main objective is not to fit the data in all dimensions, but rather to illustrate that the model with heterogeneous agents improves significantly on the representative agent case in the desired direction compared to the data. The representative agent version is one in which only shareholders (T1) are present in the economy but all other parameters remain the same (the distribution risk is not active in that economy and risk aversion is kept at 4). The results in Tables 3 and 4 are based on the unconditional moments of a second order approximation of the model.

\footnotetext{
${ }^{10}$ See Rios-Rull and Santaeulalia-Llopis (2008) for a discussion of the distributive consequences of TFP shocks.

${ }^{11}$ In a previous version of this paper, we also considered nominal rigidities and demand shocks. It turned out that the demand shocks contributed indeed significantly to the risk premium.
} 
Table 4

Macroeconomic statistics.

\begin{tabular}{|c|c|c|c|c|c|c|c|c|c|c|c|}
\hline & $\sigma_{Y}$ & $\sigma_{I}$ & $\rho_{I, Y}$ & $\sigma_{\mathrm{C}}$ & $\rho_{C, Y}$ & $\sigma_{N}$ & $\rho_{N, Y}$ & $\sigma_{W}$ & $\rho_{W, Y}$ & $\sigma_{W N / Y}$ & $\rho_{W N / Y, Y}$ \\
\hline \multicolumn{12}{|l|}{ Data } \\
\hline $\begin{array}{l}1947-2008 \\
\text { Models }\end{array}$ & 1.72 & 4.94 & 0.76 & 1.17 & 0.79 & 1.34 & 0.87 & 0.78 & 0.09 & 2.34 & -0.19 \\
\hline $\mathrm{T} 1+\mathrm{T} 2+\mathrm{T} 3$ & 1.72 & 3.30 & 0.96 & 1.34 & 0.98 & 0.98 & 1.00 & 0.68 & 0.08 & 3.02 & -0.20 \\
\hline $\mathrm{T} 1+\mathrm{T} 3\left(\varepsilon^{z}, \varepsilon^{v}, \rho\right)$ & 1.72 & 3.46 & 0.95 & 1.33 & 0.97 & 0.98 & 1.00 & 0.86 & -0.15 & 3.95 & -0.20 \\
\hline $\mathrm{T} 1+\mathrm{T} 3\left(\varepsilon^{z}, \varepsilon^{v}\right)$ & 1.72 & 2.89 & 0.89 & 1.53 & 0.97 & 0.98 & 1.00 & 1.09 & 0.38 & 3.66 & -0.08 \\
\hline $\mathrm{T} 1+\mathrm{T} 3\left(\varepsilon^{z}\right)$ & 1.72 & 2.57 & 1.00 & 1.49 & 1.00 & 0.98 & 1.00 & 0.42 & 1.00 & 0.74 & -0.38 \\
\hline $\mathrm{T} 1+\mathrm{T} 2$ & 1.72 & 2.57 & 1.00 & 1.49 & 1.00 & 0.98 & 1.00 & 0.74 & 1.00 & 0.00 & 0.00 \\
\hline $\mathrm{T} 1$ & 1.72 & 2.16 & 1.00 & 1.61 & 1.00 & 0.98 & 1.00 & 0.74 & 1.00 & 0.00 & 0.00 \\
\hline
\end{tabular}

Note: The data come from the FRED database at the St. Louis Fed and the BLS. All real variables have been detrended with the Hodrick-Prescott filter except for the wage share. The output correlation of the wage share is the correlation between HP-filtered output and the unfiltered wage share.

Overall, the baseline model with three types of heterogeneous agents fits the data well both in terms of real and financial statistics. That the model matches the real statistics is not a surprise given that we estimated its stochastic structure on the main aggregate variables. From that perspective, the reported model statistics confirm the relative success of the model fit. ${ }^{12}$ The financial moments were not used in the estimation, and these moments provide therefore a very strong validity test for the model.

In terms of the real statistics, the model reproduces the observed aggregate output volatility by construction through the scaling of the innovations (1.72\%). Hours worked are less volatile compared to the data (0.98 versus 1.34$)$, but the model reproduces the high correlation between total hours and output. The consumption volatility is too high (1.34 versus 1.17 ), while investment is not sufficiently volatile (3.30 versus 4.94 ). Both demand components display an excessive correlation with output. Decreasing the capital adjustment costs can improve these real statistics but would reduce the risk premiums also. Another explanation is the very persistent nature of the two structural shocks that we consider and the fact that we disregard the less persistent shocks that were captured by the measurement errors in our estimation procedure. Simply lowering the persistence of the structural shocks improves the relative volatility and lowers the correlations with output, but this has a cost in terms of the financial statistics. Results would improve on both sides if we allow for the additional, less persistent sources of risk in the model. For instance, the introduction of investment-specific technology shocks or shocks to financial frictions, suggested in recent literature as important alternative sources of volatility, could increase the volatility of investment and reduce the variation and the procyclical nature of consumption. Real wages and the wage share behave very much in line with the data, both in terms of volatility and cyclical behavior: real wages are smooth and acyclical, while the wage share is relatively volatile and behaves countercyclically. We consider these last results as very important features of the model, since the income distribution plays a crucial role for the volatility of the capital returns and therefore also for the pricing of the underlying assets.

On the financial side, the model is able to generate an important risk premium both for equity $(E P=5.18)$ and for the holding period return on a 10 -year bond $(B P=2.34)$. For the bond, this excess holding period return corresponds with a yield spread $\left(y^{40}-R^{f}\right)$ of 1.81 . The model generates a risk free real rate $\left(R^{f}\right)$ of $1.26 \%$ with a standard deviation of 1.98 . The volatility of the return to equity is 22.18 , which yields a Sharpe ratio (SR) of 0.24 . These statistics are close to the observed data averages. We slightly underestimate the equity risk premium and the $S R$, while we tend to overestimate the spread in the bond returns. In sum, the model passes relatively successfully the validity test on the financial moments.

The baseline model generates the following wealth distribution: $85 \%$ of financial assets are held by the top $10 \%$ of the population that consists of shareholders, $15 \%$ of financial wealth is held by the next $30 \%$ of the population that is represented by the bondholders, and $0 \%$ is held by the workers. The shareholdings are-by definition-concentrated in the first group. This distribution implies a concentration of wealth and stock market participation that is very similar to the one typically measured in the US wealth distribution (see, e.g., Wolff, 2006). ${ }^{13}$ In the model, the shareholders' financial portfolio consists of $93 \%$ stocks and $7 \%$ bonds.

The relative contributions of heterogeneity and distribution risk across agents become clear when we compare these outcomes with versions of the model in which only one or two types of agents are present. When only type 1 agents are present, the model reduces to the standard representative agent (RA) model. In such a setup only aggregate productivity risk matters as distribution shocks are not active. The failure of the representative agent model to explain the observed risk premiums in a model with endogenous capital and labor decisions is documented widely in the literature (see, e.g., Jermann, 1998; Lettau and Uhlig, 2000; Boldrin et al., 2001; Uhlig, 2007, ...). The risk premium on equity (0.87\%) remains small because aggregate consumption is relatively smooth and the return on equity displays only modest volatility. The same applies for the risk premium on bonds $(0.54 \%)$ and the term spread $(0.34 \%)$ because the volatility in interest rates and bond prices remains low. So both the price of risk, determined by the volatility in marginal utility, and the amount of risk, depending on the volatility in the returns, are insufficient

\footnotetext{
${ }^{12}$ We disregard the measurement errors in this exercise and rescale the variance of the two structural shocks so that the model can still match exactly with the volatility of aggregate output.

${ }^{13}$ Over the last two decades, there has been an increasing share of the population that participates in the stock market. An interesting extension of the paper would be to analyze the implications of this increase in stock market participation for the risk premium.
} 
to generate the observed risk premiums. The fact that the RA model still generates a non-negligible risk premium is mainly explained by the GHH-preferences, so that labor supply is not effectively used to smooth consumption further, and the assumption of a substantial risk aversion (equal to 4 for type 1 agents).

These results do not change much when we introduce a distinction between bondholders and shareholders (T1+T2). Here we assume that bondholders make up $80 \%$ of the households and that their utility function is characterized by a lower elasticity of intertemporal substitution (0.1) than for the shareholders (0.25). Both types of agents supply labor at the competitive wage, such that only aggregate risk matters as in the RA model. The lower IES implies that bondholders value smooth consumption more than the shareholders. Aggregate consumption becomes smoother compared to the RA-case, but the consumption of shareholders is more volatile than consumption of bondholders. In periods of high productivity, the additional savings decrease the risk free interest rate more which induces higher equity prices and a stronger increase in investment. The volatility in shareholders' consumption, the interest rate and the return to equity is, however, not sufficient to lift the risk premiums considerably.

Heterogeneity between workers and shareholders and a labor contract that is affected by both productivity and distribution risk produce much stronger effects. This becomes clear when we look at the results from a model with only these two types of agents, again in a proportion of $80 \%$ and $20 \%$. Two additional mechanisms explain this result. First, consider the case in which there is only aggregate productivity risk (T1+T3 $\left(\varepsilon^{z}\right)$ ): this means that we eliminate the effect of productivity shocks on the bargaining power of workers/shareholders in the labor contract and also disregard any additional independent distribution risk. Under these assumptions, the macrovariables behave the same in the model with workers and an efficient labor contract, as in the model with bondholders and bond trade (T1+T2). But the labor contract implies a redistribution of wealth between workers and shareholders. ${ }^{14}$ After a positive productivity shock workers moderate their wage claims in order to smooth their consumption. As a result, the wage share declines. Shareholders-who benefit from the higher income from capital-increase their consumption more. Therefore, the labor contract induces additional volatility both in the return to equity and in shareholders' consumption. As a consequence, with productivity risk alone, the model with workers and shareholders produces a risk premium of $1.64 \%$. This is markedly higher than the model with bondholders but still far below the empirically observed risk premium.

Next, we introduce distribution risk in the labor contract, without allowing for the estimated correlation between the two sources of risk $\left(\mathrm{T} 1+\mathrm{T} 3\left(\varepsilon^{z}, \varepsilon^{v}\right)\right)$. Distribution risk raises the volatility in the real wage and the wage share. Clearly, this has important implications for the financial side as both the return to equity and the consumption of shareholders become much more volatile. Indeed, the risk premium on equity and the SR increase to $4.41 \%$ and 0.22 , respectively.

When positive aggregate productivity shocks also induce a lower bargaining for workers in the labor $\operatorname{contract}\left(\mathrm{T} 1+\mathrm{T} 3\left(\varepsilon^{z}, \varepsilon^{v}, \rho\right)\right.$ ), as we estimated in the overall model, the risk premium on equity goes up to $6.72 \%$ and overshoots the empirically observed premium. The highly countercyclical real wage and wage share are clearly responsible for this outcome as sources of additional volatility in the shareholder stochastic discount factor and the return to capital. The volatility and, especially, the persistence in the short rate makes bond prices also excessively volatile, so that the model term premium becomes very high.

\subsection{Risk sharing across agents}

In a model with heterogeneous agents and a complete market of contingent claims, one can easily show that the optimal risk sharing between agents results in a constant relative marginal utility:

$$
\frac{U_{i, t}^{C}}{U_{j, t}^{C}}=\frac{U_{i, t+1}^{C}}{U_{j, t+1}^{C}}=\tau
$$

where $i$ and $j$ index agent types $(=1,2,3$ and $i \neq j)$ and $\tau$ depends on the relative wealth of the two agents. In our setup, there are no contingent claims and we also assume that types 2 and 3 agents have no access to the stock market. Instead, we consider two alternative risk sharing arrangements: the bond market and the labor contract. Fig. 1 summarizes the consumption/savings decision of the different agents in case of a positive productivity shock. The impulse response functions (IRF) are based on a first order approximation of the model around a steady state in which the bondholders have zero net bond holdings. For all three agents the higher current and expected income increases their wealth and drives up their consumption. In addition to the impulse response in the baseline model, the figure plots the quantitative effect of the different channels of risk sharing.

\subsubsection{The bond market}

Type 2 agents' only recourse to smooth their marginal utility is the bond market. By selling and buying bonds to/from the shareholders, these two types of agents will try to achieve the equalization of their relative marginal utilities over time. ${ }^{15}$

\footnotetext{
14 At least when considering a positive productivity shock in isolation; with ongoing worker-firm relations these effects will largely cancel out over time and result in an average contract wage that is lower than the average spot wage in the stochastic steady state.

15 The bond market provides only an imperfect risk sharing device for the bondholders as they are confronted with an effective interest rate that will deviate from the market rate: the financial intermediation margin depends on their net wealth position and imposes the intertemporal consumption constraint on their consumption decision. As mentioned before, the magnitude of this cost does not affect the quantitative results presented in the paper.
} 

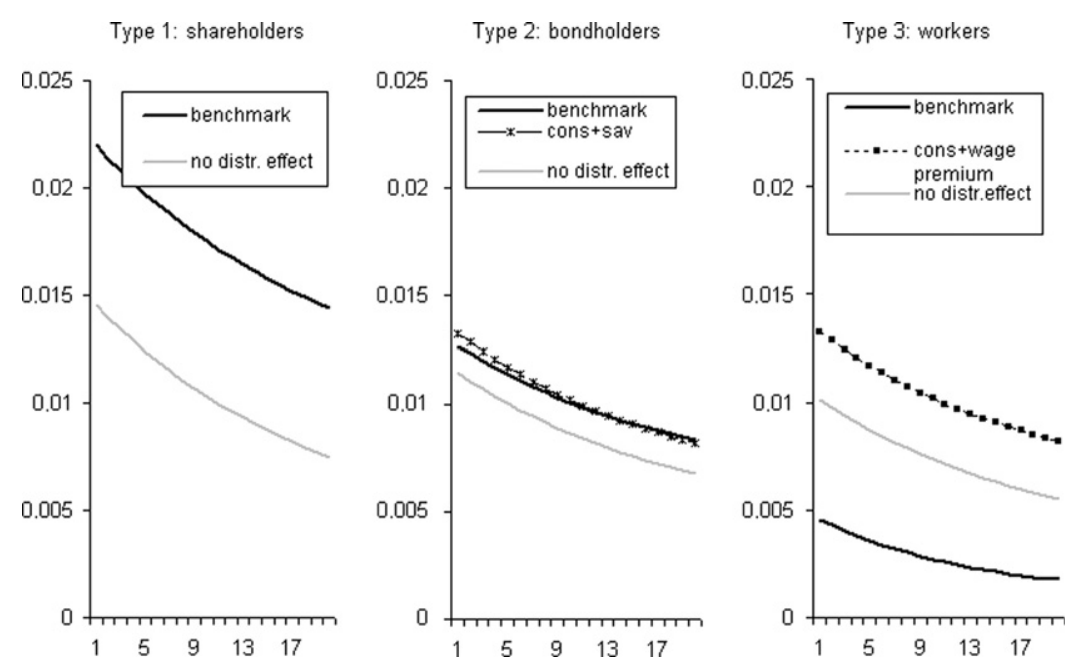

Fig. 1. Consumption dynamics for the three agents (one std. err. productivity shock). Note: Solid black lines denote the consumption response of the different agents in the benchmark model. For bondholders (middle panel), the additional dashed line measures the sum of their consumption and the bond trade in the benchmark model. For workers (right panel), the dashed line measures the sum of their consumption and the wage premium, also in the benchmark model. The grey solid lines are consumption responses in the model without the distributional effect of productivity shocks.

Bondholders have a relatively low IES and therefore a strong desire to smooth consumption. Consequently, following a positive productivity shock they will save part of the increased income. Given the fixed supply of bonds by the firms, shareholders will have to absorb this supply of funds. Shareholders will be eager to do so and raise their consumption plans given their higher IES. It follows that the risk sharing through the bond market between types 1 and 2 agents increases the volatility of shareholders' consumption, which will tend to increase the risk premium relative to an economy in which these agents are not allowed to trade in the bond market.

This conclusion is qualitatively similar to the results obtained by Guvenen (2009). However, the IRFs clearly indicate that the size of this bond trade (=savings, the difference between the black solid and dashed lines in the middle panel of Fig. 1) remains very limited in our model. It is interesting to note that the bond trade between bondholders and shareholders is smaller in the model with three agents and distribution risk than in the model with shareholders and bondholders only. In this last model, the reaction of the bond trade is four times bigger than in the IRF reported in Fig. 1. When we use the calibration of Guvenen for the productivity shock, in his model with exogenous labor, the bond trade becomes even ten times larger and the associated risk premium increases to $4 \%$. So while the mechanism of Guvenen surely has the potential to generate substantial risk premiums, it does not in our more general setup, for our estimated stochastic structure. The reason for this limited bond trading in the complete model is that shareholder income will rise substantially more as a consequence of the wage moderation that results from the labor contract. Therefore, shareholders will be more reluctant to absorb the additional savings from the bondholders. As a result, interest rates will decrease further and bondholders will find it optimal to raise consumption more and save less. So the income redistribution effects present in the three-agent model offset the importance of the bond trade mechanism that is central to the Guvenen model.

\subsubsection{The labor contract}

Fig. 1 also shows the impact of the insurance premium on workers' and shareholders' consumption following a positive productivity shock. The contract wage will increase less than the spot wage, meaning that the insurance premium received by the workers is negative. This helps to stabilize the consumption of the workers. The opposite holds of course for the shareholders, who receive the additional dividends of the firms. Their consumption volatility would be much less outspoken without the labor contract. Danthine and Donaldson (2002) refer to this mechanism as the operational leverage, in analogy with the firm debt service that generates financial leverage.

Fig. 1 also illustrates the outcome of a productivity shock for consumption in the model in which the distributive effects of a productivity shock are absent. Without this correlation, the volatility of shareholder consumption is more in line with that of the other agents. Recall that this correlation between productivity and distribution risk reinforces the decline in the wage share following the positive productivity shock, in line with the observed evidence in the data. The fact that workers get a smaller piece of the (bargaining) pie in a boom implies that profits become more procyclical. The correlation translates into more volatile, procyclical shareholder consumption.

In sum, the contract wage and the redistributive effects of a productivity shock both contribute to smoothing workers' labor income and consumption. In doing so, they also exacerbate the cyclical reaction of shareholders' consumption. Therefore, both mechanisms help to increase the risk premium in the model. 
Table 5

Financial statistics: stochastic structure.

\begin{tabular}{|c|c|c|c|c|c|c|c|c|c|c|}
\hline & $S R$ & $E P$ & $B P$ & $y^{40}-R^{f}$ & $R^{f}$ & $\sigma_{R^{f}}$ & $\sigma_{R^{s}}$ & $\sigma_{\mathrm{C} 1}$ & $\sigma_{\mathrm{C} 2}$ & $\sigma_{\mathrm{C} 3}$ \\
\hline $\begin{array}{l}\text { Baseline: } \varepsilon^{z}, \varepsilon^{v}, \rho \\
\text { Volatility }\end{array}$ & 0.24 & 5.18 & 2.34 & 1.81 & 1.26 & 1.98 & 22.18 & 3.23 & 1.66 & 1.28 \\
\hline$\varepsilon^{z}$ & 0.12 & 1.60 & 0.90 & 0.59 & 3.33 & 1.56 & 13.47 & 1.88 & 1.48 & 1.32 \\
\hline$\varepsilon^{v}$ & 0.14 & 1.75 & 0.58 & 0.49 & 2.93 & 0.77 & 11.80 & 1.79 & 0.30 & 1.35 \\
\hline $\begin{array}{l}\varepsilon^{Z}, \varepsilon^{D} \\
\text { Persistence }\end{array}$ & 0.19 & 3.35 & 1.48 & 1.11 & 2.22 & 1.74 & 17.91 & 2.61 & 1.51 & 1.88 \\
\hline$\rho^{z} * 0.9$ & 0.23 & 5.00 & 2.45 & 1.77 & 1.53 & 2.98 & 22.64 & 2.99 & 1.47 & 1.28 \\
\hline$\rho^{v} * 0.9$ & 0.18 & 3.77 & 2.20 & 1.41 & 2.45 & 2.84 & 21.15 & 2.57 & 1.63 & 1.38 \\
\hline
\end{tabular}

Table 6

Macroeconomic statistics: stochastic structure.

\begin{tabular}{|c|c|c|c|c|c|c|c|c|c|c|c|}
\hline & $\sigma_{Y}$ & $\sigma_{I}$ & $\rho_{I, Y}$ & $\sigma_{C}$ & $\rho_{C, Y}$ & $\sigma_{N}$ & $\rho_{N, Y}$ & $\sigma_{W}$ & $\rho_{W, Y}$ & $\sigma_{W N / Y}$ & $\rho_{W N / Y, Y}$ \\
\hline $\begin{array}{l}\text { Baseline: } \varepsilon^{z}, \varepsilon^{v}, \rho \\
\text { Volatility }\end{array}$ & 1.72 & 3.30 & 0.96 & 1.34 & 0.98 & 0.98 & 1.00 & 0.68 & 0.08 & 3.02 & -0.20 \\
\hline$\varepsilon^{z}$ & 1.72 & 2.64 & 1.00 & 1.47 & 1.00 & 0.98 & 1.00 & 0.49 & 1.00 & 0.64 & -0.34 \\
\hline$\varepsilon^{v}$ & 0.05 & 1.02 & -0.05 & 0.29 & 0.25 & 0.03 & 1.00 & 0.81 & 0.14 & 2.63 & 0.02 \\
\hline$\varepsilon^{z}, \varepsilon^{D}$ & 1.72 & 2.83 & 0.93 & 1.50 & 0.98 & 0.98 & 1.00 & 0.94 & 0.52 & 2.79 & -0.08 \\
\hline \multicolumn{12}{|l|}{ Persistence } \\
\hline$\rho^{z} * 0.9$ & 1.64 & 3.44 & 0.97 & 1.20 & 0.98 & 0.94 & 1.00 & 0.70 & 0.05 & 2.82 & -0.19 \\
\hline$\rho^{v} * 0.9$ & 1.72 & 4.05 & 0.90 & 1.28 & 0.93 & 0.99 & 1.00 & 0.77 & 0.03 & 1.46 & -0.42 \\
\hline
\end{tabular}

\section{Sensitivity analysis of the model}

Here we analyze how sensitive the results are to changes in different aspects of the model. We consider the sensitivity to the stochastic structure, the choice of the functional form of the utility functions, the important structural parameters, the heterogeneity in preferences among different agents.

\subsection{The stochastic structure}

The role of the different sources of risk was discussed in the previous section for the model in which only workers and shareholders are present. These conclusions generally also apply to the complete model with three agents (but with some additional insights). Tables 5 and 6 summarize the results.

Aggregate productivity shocks, distribution shocks and the correlation between these two shocks contribute equally to the risk premium for equity, but distribution risk is less important for the bond premium. Productivity risk is the main source of variation in the short rate and in the main macro aggregates. Aggregate productivity has some distributional effects through the contract wage, but without the additional distribution risk this is insufficient to explain the wage share volatility or to generate sufficient volatility in the equity returns. Distribution risk as such affects aggregate output only marginally, but it is crucial to match the wage statistics. The absence of intertemporal reallocations explains its weak effect on the short rate and therefore also on the bond premium.

Persistence in the exogenous processes, especially in the distribution process, is important to generate larger risk premiums, while it entails more volatility in the short rate. With less persistence in the shocks, consumption smoothing generates larger savings flows. Consequently, interest rates have to adjust more in order to induce firms to adjust their capital accumulation accordingly.

\subsection{The utility specification}

In the baseline model, we retained the GHH utility function for describing the preferences of the three types of agents. This choice of the utility function deserves some more discussion because it is crucial for the joint dynamics of the real and the financial decisions in the model. Its importance derives from the fact that marginal utility enters both in the stochastic discount factor for asset pricing and in the labor supply decision.

In the comparison of the heterogeneous agent model with a representative agent model, we also consider two alternative utility functions. In particular, the standard separable utility function and the King, Plosser, and Rebelo (1988, 
henceforth KPR) preferences are specified as ${ }^{16}$

$$
\begin{aligned}
& \text { SEP : } U_{t}=\frac{C_{t}^{1-\sigma}}{1-\sigma}-\psi \frac{N_{t}^{\phi}}{\phi} \\
& \text { KPR : } U_{t}=\frac{\left(C_{t}\left(1-\psi N_{t}^{\phi}\right)\right)^{1-\sigma}}{1-\sigma}
\end{aligned}
$$

To focus ideas, let us start from the case of a representative agent with a CRRA utility function and separability between consumption and labor. ${ }^{17}$ The equity premium $\left(E P_{t}^{A}\right)$ can be written as

$$
E P_{t}^{A}=-\rho_{r s, \Delta \lambda} \sigma_{r s} \sigma_{\Delta \lambda}=\sigma \rho_{r s, \Delta c} \sigma_{r s} \sigma_{\Delta c}
$$

where $\sigma$ and $r s$ stand for the risk aversion and the return on stocks, $\Delta \lambda=\lambda_{t+1}-\lambda_{t}, \lambda_{t}=\partial U\left(C_{t}\right) / \partial C_{t}=U_{t}^{C}$, and $\sigma_{x}$ and $\rho_{x}$ denote the (conditional) standard deviation and correlation, respectively. The corresponding Sharpe ratio $\left(S R_{t}^{A}\right)$ is

$$
S R_{t}^{A}=-\rho_{r s, \Delta \lambda} \sigma_{\Delta \lambda}=\sigma \rho_{r s, \Delta c} \sigma_{\Delta c}
$$

The price of risk depends on the volatility of consumption growth, on the correlation between consumption and the return on capital, and on the degree of risk aversion.

The agent also has the opportunity to adjust her labor supply to smooth fluctuations in marginal utility. The linearized first order condition relates the supply of labor to real wages and consumption:

$$
(\phi-1) \hat{n}_{t}=\hat{w}_{t}-\sigma \hat{c}_{t}
$$

Following a positive productivity shock, the increase in consumption, ceteris paribus, lowers the marginal utility of the real wage, which reduces labor supply. The reduction in working hours, in turn, mitigates the initial expansionary effects of the productivity shock. As a result, the rise in both marginal productivity (and thus the stock return $r s$ ) and consumption (and thus volatility of marginal utility $\sigma_{\Delta \lambda}$ ) will be smaller. Increasing the degree of risk aversion, which can contribute to the risk premium in a model with exogenous labor, will induce a more intensive utilization of the labor supply to smooth consumption. ${ }^{18}$ The analytical expressions above reveal that there is no hope of improving asset pricing implications by allowing for endogenous labor in a separable utility framework. Moreover, in terms of macro implications, these results do not yield the observed positive correlation between labor inputs and output.

The introduction of non-separability between labor and consumption in the utility function strongly affects the model's macro and financial responses. The corresponding Sharpe ratio becomes (see, e.g., Uhlig, 2007):

$$
S R_{t}=\rho_{r s, \Delta c} \eta_{c c} \sigma_{\Delta c}-\rho_{r s, \Delta n} \eta_{c n, n} \sigma_{\Delta n}
$$

where $\eta_{c c}=-U^{C C} * C / U^{C}$ is the relative risk aversion with respect to consumption. The cross-derivative $\eta_{c n, n}$ measures the degree of non-separability in the utility function: $\eta_{c n, n}=U^{C N} * N / U^{C}>0$ (complements) $<0$ (substitutes).

The first term in (26) implies that the price of risk increases with the correlation between consumption and stock returns, the risk aversion, and the volatility of consumption growth. This is the traditional mechanism also at work in the representative agent model with exogenous labor and separable utility. Non-separability leads to an additional effect depending on the volatility of labor supply, the cross-derivative of marginal utility with respect to hours worked, and the correlation between hours worked and the return on equity. The sign of this term depends on the cross-derivative and the correlation. Both correlation terms in the Sharpe ratio are generally high and positive.

On the macro side, the linearized FOC for labor supply can be written as

$$
\left(\eta_{c c}+\eta_{n c, c}\right) \hat{c}_{t}-\left(\eta_{n n}+\eta_{c n, n}\right) \hat{n}_{t}=\hat{w}_{t}
$$

Eq. (27) shows that the strength of the income and substitution effects on labor supply are also controlled by the crossderivatives of the utility function to its respective arguments. This means that introducing non-separabilities in utility does not just buy some free parameters to scale up asset pricing moments, such as the Sharpe ratio. By contrast, we impose discipline on the exercise by examining a selection of both financial and macroeconomic moments. To aid intuition, Table 7 summarizes the implied elasticities for each of the three preference specifications we consider.

\footnotetext{
${ }^{16}$ Our choice for these utility functions is motivated by the following considerations. First, they allow us to assess the effect of non-separability rigorously, as we will document below. Second, the KPR specification is consistent with a balanced growth path, which is a desirable feature for future extensions of the model, and for taking the model to the data more rigorously. Third, one can interpret the GHH utility function as one limit case of Jaimovich and Rebelo (2009, JR) preferences, with KPR utility being on the other end of the spectrum. JR preferences are specified as $U_{t}=\left(\left(C_{t}-\psi N_{t}^{\phi} X_{t}\right)^{1-\sigma}\right) /(1-\sigma)$ where $X_{t}=C_{t}^{\gamma} X_{t-1}^{(1-\gamma)}$, with $0<\gamma<1$. The interpretation of GHH preferences as an extreme case of JR preferences, with $\gamma \rightarrow 0$, responds to the critique that GHH preferences are inconsistent with a balanced growth path. It implies that the wealth effect on labor supply is realized only very slowly over time, but in the long run this wealth effect exactly offsets the substitution effect on labor supply. The cases we checked with JR utility, typically gave intermediate results between $\operatorname{KPR}(\gamma=0)$ and GHH $(\gamma=1)$, so we restrict our analysis to these two limit cases.

${ }^{17}$ There are numerous variations on this basic representative agent framework, and our goal is not to provide a detailed overview (see, e.g., Kocherlakota, 1996). Rather, we here focus on the role of introducing the labor decision.

${ }^{18}$ Even in a model with exogenous labor, a higher degree of risk aversion is not an option for solving the equity premium puzzle as it generates the so-called risk free rate puzzle.
} 
The analytical expressions in the first two rows of the table help to evaluate the Sharpe ratio, while the lower two rows are crucial to determine the labor supply reaction. The cross-derivative terms affect both the SR in Eq. (26) and the labor supply decision in Eq. (27). Under KPR and GHH utility, consumption and labor are complements (see Table 7: $\eta_{c n, n}=(\sigma-1)>0$ under KPR and $\eta_{c n, n}=\sigma(\phi /(\phi-1))>0$ under GHH). In other words, agents will prefer positive comovement between consumption and labor, and the negative income effect on labor supply $\left(\eta_{c c}+\eta_{n c, c}\right)$ is reduced to 1 under KPR preferences, while the effect drops to zero under GHH preferences. However, if hours worked become procyclical, so that the correlation $\rho_{r s, \Delta n}$ is positive, and the cross-derivative is positive, then the second term in the SR in Eq. (26) has a negative effect on the price of risk. Hence, during a recession-when marginal utility is high due to low consumption - the reduction in hours worked will mitigate or even offset this increase in marginal utility.

In sum, non-separability can help by alleviating the strong income effects at work in the first order condition for labor supply under separable utility. This will reduce the strong countercyclical nature of employment, which reinforces the propagation of the productivity shock. However, because labor and consumption are complements, their comovement will also tend to stabilize marginal utility. This, in turn, limits the model's ability to generate significant risk premiums. Given that GHH preferences overcome - at least to some extent — the important problems of the separable utility function, we retain these preferences for all our versions of the heterogeneous agents model that we consider in this paper (see also Guvenen, 2009).

To illustrate this discussion we summarize in Tables 8 and 9 the results of the three utility functions for the representative agent version and the three-agent model. In the T1 (representative agent) model with separable utility and

Table 7

Implied elasticities for utility functions

\begin{tabular}{|c|c|c|c|}
\hline & SEP & KPR & $\mathrm{GHH}$ \\
\hline$\eta_{c c}$ & $\sigma$ & $\sigma$ & $\sigma \frac{\phi}{\phi-1}$ \\
\hline$\eta_{c n, n}$ & 0 & $(\sigma-1)$ & $\sigma \frac{\phi}{\phi-1}$ \\
\hline$\eta_{c c}+\eta_{n c, c}$ & $\sigma$ & 1 & 0 \\
\hline$\eta_{n n}+\eta_{c n, n}$ & $-(\phi-1)$ & $-\phi$ & $-(\phi-1)$ \\
\hline
\end{tabular}

Note: This table assumes $C=W N$.

Table 8

Financial statistics: utility specifications.

\begin{tabular}{|c|c|c|c|c|c|c|c|c|c|c|}
\hline & $S R$ & $E P$ & $B P$ & $y^{40}-R^{f}$ & $R^{f}$ & $\sigma_{R^{f}}$ & $\sigma_{R^{s}}$ & $\sigma_{C 1}$ & $\sigma_{C 2}$ & $\sigma_{\mathrm{C} 3}$ \\
\hline 1947-2007 & 0.39 & 6.11 & 1.06 & 1.34 & 1.19 & 2.84 & 15.50 & - & - & - \\
\hline $1926-2007$ & 0.26 & 5.85 & 1.76 & - & 0.60 & 5.27 & 22.35 & - & - & - \\
\hline \multicolumn{11}{|l|}{ T1-model } \\
\hline SEP & 0.03 & 0.09 & 0.06 & 0.02 & 4.00 & 0.45 & 3.17 & - & - & - \\
\hline KPR & 0.06 & 0.36 & 0.24 & 0.13 & 3.88 & 0.86 & 6.34 & - & - & - \\
\hline $\mathrm{GHH}$ & 0.09 & 0.87 & 0.54 & 0.34 & 3.63 & 1.23 & 9.64 & - & - & - \\
\hline $\mathrm{GHH} \sigma=10$ & 0.16 & 2.10 & 1.39 & 1.00 & 2.73 & 1.76 & 13.14 & - & - & - \\
\hline \multicolumn{11}{|l|}{$\mathrm{T} 1+\mathrm{T} 2+\mathrm{T} 3$ model } \\
\hline SEP & 0.12 & 1.72 & 0.77 & 0.55 & 3.27 & 1.24 & 13.87 & 2.02 & 0.47 & 0.64 \\
\hline KPR & 0.17 & 3.24 & 1.43 & 1.06 & 2.51 & 1.62 & 18.62 & 2.40 & 0.98 & 0.79 \\
\hline GHH (= Baseline) & 0.24 & 5.18 & 2.34 & 1.81 & 1.26 & 1.98 & 22.18 & 3.23 & 1.66 & 1.28 \\
\hline
\end{tabular}

Table 9

Macroeconomic statistics: utility specifications.

\begin{tabular}{|c|c|c|c|c|c|c|c|c|c|c|c|}
\hline & $\sigma_{Y}$ & $\sigma_{I}$ & $\rho_{I, Y}$ & $\sigma_{C}$ & $\rho_{C, Y}$ & $\sigma_{N}$ & $\rho_{N, Y}$ & $\sigma_{W}$ & $\rho_{W, Y}$ & $\sigma_{W N / Y}$ & $\rho_{W N / Y, Y}$ \\
\hline 1947-2008 & 1.72 & 4.94 & 0.76 & 1.17 & 0.79 & 1.34 & 0.87 & 0.78 & 0.09 & 2.34 & -0.19 \\
\hline \multicolumn{12}{|l|}{ T1-model } \\
\hline SEP & 0.51 & 0.71 & 1.00 & 0.46 & 1.00 & 0.75 & -1.00 & 1.26 & 1.00 & - & - \\
\hline KPR & 1.06 & 1.42 & 1.00 & 0.96 & 1.00 & 0.04 & 1.00 & 1.02 & 1.00 & - & - \\
\hline GHH & 1.72 & 2.16 & 1.00 & 1.61 & 1.00 & 0.98 & 1.00 & 0.74 & 1.00 & - & - \\
\hline $\begin{array}{l}\text { GHH } \sigma=10 \\
\mathbf{T} 1+\mathbf{T} 2+\mathbf{T} 3 \text { model }\end{array}$ & 1.72 & 2.94 & 1.00 & 1.39 & 1.00 & 0.98 & 1.00 & 0.74 & 1.00 & - & - \\
\hline SEP & 0.87 & 1.95 & 0.99 & 0.58 & 0.99 & 0.31 & -0.70 & 0.80 & 0.56 & 2.16 & -0.26 \\
\hline KPR & 1.15 & 2.57 & 0.97 & 0.80 & 0.98 & 0.20 & 0.88 & 0.76 & 0.30 & 2.89 & -0.23 \\
\hline GHH (=Baseline) & 1.72 & 3.30 & 0.96 & 1.34 & 0.98 & 0.98 & 1.00 & 0.68 & 0.08 & 3.02 & -0.20 \\
\hline
\end{tabular}


Table 10

Financial statistics: structural parameters.

\begin{tabular}{|c|c|c|c|c|c|c|c|c|c|c|}
\hline & $S R$ & $E P$ & $B P$ & $y^{40}-R^{f}$ & $R^{f}$ & $\sigma_{R^{f}}$ & $\sigma_{R^{s}}$ & $\sigma_{C 1}$ & $\sigma_{C 2}$ & $\sigma_{\mathrm{C} 3}$ \\
\hline 1947-2007 & 0.39 & 6.11 & 1.06 & 1.34 & 1.19 & 2.84 & 15.50 & - & - & - \\
\hline 1926-2007 & 0.26 & 5.85 & 1.76 & - & 0.60 & 5.27 & 22.35 & - & - & - \\
\hline Baseline & 0.24 & 5.18 & 2.34 & 1.81 & 1.26 & 1.98 & 22.18 & 3.23 & 1.66 & 1.28 \\
\hline$\phi=3$ & 0.26 & 6.38 & 2.72 & 2.14 & 0.69 & 2.06 & 24.87 & 3.73 & 1.42 & 1.63 \\
\hline$\xi=0.3$ & 0.27 & 7.27 & 3.52 & 2.62 & 0.38 & 2.64 & 27.13 & 3.66 & 1.72 & 1.30 \\
\hline$\mu=0.4$ & 0.24 & 6.01 & 2.34 & 1.81 & 1.26 & 1.98 & 25.72 & 3.23 & 1.66 & 1.28 \\
\hline
\end{tabular}

Note: Baseline parameter values are $\phi=1.75, \xi=0.5, \mu=0.3$.

Table 11

Macroeconomic statistics: structural parameters.

\begin{tabular}{|c|c|c|c|c|c|c|c|c|c|c|c|}
\hline & $\sigma_{Y}$ & $\sigma_{I}$ & $\rho_{I, Y}$ & $\sigma_{C}$ & $\rho_{C, Y}$ & $\sigma_{N}$ & $\rho_{N, Y}$ & $\sigma_{W}$ & $\rho_{W, Y}$ & $\sigma_{W N / Y}$ & $\rho_{W N / Y, Y}$ \\
\hline 1947-2008 & 1.72 & 4.94 & 0.76 & 1.17 & 0.79 & 1.34 & 0.87 & 0.78 & 0.09 & 2.34 & -0.19 \\
\hline Baseline & 1.72 & 3.30 & 0.96 & 1.34 & 0.98 & 0.98 & 1.00 & 0.68 & 0.08 & 3.02 & -0.20 \\
\hline$\phi=3$ & 1.34 & 3.25 & 0.94 & 0.94 & 0.94 & 0.45 & 1.00 & 0.98 & 0.00 & 4.10 & -0.20 \\
\hline$\xi=0.3$ & 1.72 & 2.73 & 0.96 & 1.48 & 0.99 & 0.98 & 1.00 & 0.68 & 0.17 & 2.88 & -0.19 \\
\hline$\mu=0.4$ & 1.72 & 3.30 & 0.96 & 1.34 & 0.98 & 0.98 & 1.00 & 0.68 & 0.08 & 3.02 & -0.20 \\
\hline
\end{tabular}

a risk aversion of 4 , the labor supply is used intensively to smooth the consumption stream. The endogenous labor decision implies that labor supply is strongly countercyclical so that the overall volatility in the economy is reduced. With a smooth consumption stream and a very low volatility in the return to capital, there is no longer a reason to require high risk premiums. A non-separable utility function goes a long way to overcome this problem even in a representative agent context. This is especially the case with GHH preferences, where the labor supply condition is no longer affected by an income effect. In that model, too, the volatility of the return to capital increases considerably. However, compared to the baseline model, the T1-GHH model yields a higher stochastic real rate and less volatility in the return on stocks. If we allow for a higher risk aversion (10) for the representative agent, the results for the financial statistics improve, but problems remain in terms of explaining the acyclical nature of wages and the variation in the wage share.

The results from the representative agent model carry over to the heterogeneous agent model. ${ }^{19}$ In contrast to GHH preferences, the labor supply under SEP and KPR depends on the consumption level, which implies that hours worked will react differently to shocks across agents. Heterogeneity improves the performance of the models for any specification of the preferences.

\subsection{The structural parameters}

Tables 10 and 11 illustrate the impact of three important structural parameters of the model: the Frisch elasticity of labor supply, the capital adjustment costs and the financial leverage of firms. In the baseline model, the values for $\phi$, $\xi$ and $\mu$ were set at values that are quite standard for calibrated models, but a large empirical uncertainty persists on these values. We therefore show the sensitivity of the results to these values. In addition, this robustness exercise helps to understand the model further.

An inelastic labor supply, higher capital adjustment costs and higher financial leverage can all contribute positively to the risk premiums, but each of them has a cost in at least one other dimension.

In a first exercise, we change the Frisch elasticity from 1.33 in the baseline case to 0.5 in the alternative scenario (this corresponds with values of $\phi$ of 1.75 and 3). When labor is made more inelastic, the model has trouble producing sufficient output volatility while the wage volatility is overestimated. Aggregate consumption is also very smooth, but this masks a higher volatility in the consumption of the different agents. This is possible because consumption of the different agents, and especially that of workers, is becoming less procyclical. The reason is that distribution shocks exert stronger effects on consumption when labor is more inelastic. This follows from the fact that the second derivative of utility with respect to consumption $\left(\eta_{c c}\right)$ is a negative function of $\phi$ under GHH preferences (see Table 7). So in order to realize an exogenous change in the relative marginal utility, relative consumption now has to adjust by more. Stated differently, with labor and consumption appearing as complementary in marginal utility and as labor supply is used less to adjust marginal utility,

\footnotetext{
${ }^{19}$ Note that in this comparison, we adjust the standard deviation of the distribution shock to make it consistent with the marginal utility expressions. This occurs because the scale of the distribution risk, estimated using GHH does not apply to either SEP or KPR. The rest of the stochastic structure is left unchanged.
} 
consumption has to adjust by more. The labor contract guarantees these relative consumption streams and adjust the wage bill accordingly. It follows that the wage and the wage share also become more volatile. With distribution shocks becoming relatively more important, the model with inelastic labor still produces high risk premiums despite the decline in aggregate volatility.

The effect of higher capital adjustment costs $(\xi=0.3$ instead of 0.5$)$ is more standard. With more costly adjustment, capital accumulation will be used less to smooth consumption over time, and interest rates will have to move by more. Equity prices and returns fluctuate more reflecting the value of the existing capital stock. Increasing the risk premium through higher adjustment costs therefore implies a lower variability of investment and more variation in the short rate.

Financial leverage affects outcomes only via its impact on the dividends paid out to shareholders. Shareholders' consumption volatility, however, will be unaffected. Their total capital income remains unchanged because the additional bonds issued by firms are held by these same shareholders, since the bondholders have no reason to adjust their holdings. It follows that the equity premium is higher, but only through an excessive volatility in equity returns; the Sharpe ratio is unaffected.

\subsection{Heterogeneity across agents}

Our agents differ in two ways: they differ in participation in the capital market and in their risk aversion. Here we analyze how important the second source of heterogeneity is for the outcomes of the model. First, we consider a version of the model in which the risk aversion is equal across all agents. In a next step, we consider an Epstein-Zin recursive utility structure, and investigate whether it is the difference in risk aversion or in intertemporal elasticity of substitution that is important.

Tables 12 and 13 show that the outcomes do not change fundamentally when $\sigma_{b, w}$ is reduced from 10 to 4 in the GHH preferences of workers and bondholders. In this case, workers' desire to smooth their consumption stream is reduced, so that the optimal labor contract will allow for more variation in the wage. The same argument applies to bondholders: as a consequence these agents will trade less actively in the bond market. The result is less variability in the risk free rate and in investment. But the financial moments are not affected strongly: the premium on equity increases slightly while that for bonds decreases somewhat. In sum, the main argument for preference heterogeneity and for a relatively high risk aversion for workers is based on the improved match with the wage dynamics. These findings are in line with the conclusions of Danthine and Donaldson for their model with workers and shareholders. However, it is opposite to the conclusion of Guvenen, who shows that a model based on bond trade between bondholders and shareholders can only produce significant risk premiums with sufficient heterogeneity in the intertemporal elasticity of substitution of the two agents.

Increasing $\sigma_{s}$, the risk aversion for shareholders, from 4 to 10, so that all agents are characterized by the same high risk aversion, produces excellent statistics for the goods and labor market, and increases the Sharpe Ratio to 0.32. However, this calibration exaggerates the bond premium and the risk free rate volatility and leads to negative mean interest rates. The preference heterogeneity in our baseline model avoids these last problems.

In our baseline model with expected utility, the parameter $\sigma$ reflects both the risk aversion and the intertemporal elasticity of substitution $(=1 / \sigma)$ of agents. In order to differentiate between these two concepts, we analyze the outcomes of the model under recursive Epstein-Zin preferences. In this setup agents maximize the following discounted value of current and future utilities:

$$
U_{i, t}=\left\{(1-\beta) u_{i}\left(C_{i, t}, N_{i, t}\right)+\beta\left[E_{t}\left(U_{i, t+1}\right)^{1-\chi_{i}}\right]^{\left(1-\rho_{i}\right) /\left(1-\chi_{i}\right)}\right\}^{1 /\left(1-\rho_{i}\right)}
$$

Table 12

Financial statistics: heterogeneity.

\begin{tabular}{|c|c|c|c|c|c|c|c|c|c|c|}
\hline & $S R$ & $E P$ & $B P$ & $y^{40}-R^{f}$ & $R^{f}$ & $\sigma_{R^{f}}$ & $\sigma_{R^{s}}$ & $\sigma_{\mathrm{C} 1}$ & $\sigma_{C 2}$ & $\sigma_{C 3}$ \\
\hline 1947-2007 & 0.39 & 6.11 & 1.06 & 1.34 & 1.19 & 2.84 & 15.50 & - & - & - \\
\hline 1926-2007 & 0.26 & 5.85 & 1.76 & - & 0.60 & 5.27 & 22.35 & - & - & - \\
\hline Baseline & 0.24 & 5.18 & 2.34 & 1.81 & 1.26 & 1.98 & 22.18 & 3.23 & 1.66 & 1.28 \\
\hline$\sigma_{s, b, w}=4$ & 0.24 & 5.24 & 2.28 & 1.80 & 1.16 & 1.86 & 22.01 & 3.25 & 2.08 & 1.67 \\
\hline$\sigma_{s, b, w}=10$ & 0.32 & 7.13 & 3.60 & 2.93 & -1.04 & 2.28 & 22.83 & 1.91 & 1.76 & 1.25 \\
\hline
\end{tabular}

Table 13

Macroeconomic statistics: heterogeneity.

\begin{tabular}{|c|c|c|c|c|c|c|c|c|c|c|c|}
\hline & $\sigma_{Y}$ & $\sigma_{I}$ & $\rho_{I, Y}$ & $\sigma_{C}$ & $\rho_{C, Y}$ & $\sigma_{N}$ & $\rho_{N, Y}$ & $\sigma_{W}$ & $\rho_{W, Y}$ & $\sigma_{W N / Y}$ & $\rho_{W N / Y, Y}$ \\
\hline 1947-2008 & 1.72 & 4.94 & 0.76 & 1.17 & 0.79 & 1.34 & 0.87 & 0.78 & 0.09 & 2.34 & -0.19 \\
\hline Baseline & 1.72 & 3.30 & 0.96 & 1.34 & 0.98 & 0.98 & 1.00 & 0.68 & 0.08 & 3.02 & -0.20 \\
\hline$\sigma_{s, b, w}=4$ & 1.72 & 3.12 & 0.93 & 1.43 & 0.98 & 0.98 & 1.00 & 0.93 & 0.07 & 3.39 & -0.18 \\
\hline$\sigma_{s, b, w}=10$ & 1.72 & 3.72 & 0.96 & 1.24 & 0.98 & 0.98 & 1.00 & 0.62 & 0.26 & 2.54 & -0.20 \\
\hline
\end{tabular}


where $x$ and $\rho$ are now, respectively, the CRRA coefficient and the inverse of the intertemporal elasticity of substitution, and

$$
u_{i}\left(C_{i, t}, N_{i, t}\right)=\left(C_{i, t}-\psi_{i} N_{i, t}^{\phi}\right)^{1-\rho_{i}}
$$

These preferences imply two major changes in the model equations: one related to the agents' stochastic discount factor, another to the labor contract. The optimal labor contract that reflects optimal risk sharing among workers and shareholders can be represented as

$$
\frac{\partial U_{3, t} / \partial C_{3, t}}{\partial U_{1, t} / \partial C_{1, t}}=\frac{\partial U_{3, t} / \partial C_{3, t+1}}{\partial U_{1, t} / \partial C_{1, t+1}}
$$

In this setup, we analyze four alternative scenario's. First, we keep workers' and bondholders' intertemporal elasticity of substitution at 0.1 , but we decrease their risk aversion to 4 . The outcomes from this model are very similar to the outcomes in the baseline model with $\sigma_{2,3}=10$ and $\sigma_{1}=4$. In a second exercise, we increase the intertemporal elasticity of substitution for the workers and bondholders from 0.1 to 0.25 , while keeping their risk aversion at 10 . Again, the outcomes appear very similar to the results with expected utility and $\sigma=4$ for all agents. In a third simulation, we lower the intertemporal elasticity of substitution of the shareholders from 0.25 to 0.1 , while maintaining their risk aversion at 4 . This model is basically equivalent to the outcomes with $\sigma=10$ for all agents in our standard expected utility setup. In sum, these findings illustrate that it is the heterogeneity in intertemporal elasticity of substitution which is important in our model, not the differences in risk aversion. The risk aversion of workers and bondholders have basically no impact on the real economy or on the risk premiums. This last result is not very surprising: risk aversion of workers and bondholders can only affect the pricing of assets, which is based on the stochastic discount factor of the shareholders, by changing their real allocation decision. Only via this channel will shareholders change their evaluation of the asset prices. But it is a standard result in a recursive utility setup that the risk aversion coefficient does not affect the real decisions in a quantitatively important way. As a last experiment, we consider the case where shareholders have an intertemporal elasticity of substitution of 0.25 , but a risk aversion of 10 . This model produces again real outcomes that are similar to our baseline case, but the risk premiums are increased considerably ( $\mathrm{EP}=8.93$ and $\mathrm{BP}=4.09$ ). Risk aversion of the shareholders affects asset pricing immediately via their stochastic discount factor while keeping their real decisions unchanged at least up to first order.

We conclude this sensitivity section by briefly mentioning some variations on other assumptions of the model. Reducing the share of the shareholders in the economy tends to increase the risk premiums, especially if the share of the workers is increased as the counterbalance. For instance, if shareholders make up only $5 \%$ of the population instead of $10 \%$, and workers' weight is increased to $65 \%$, the risk premium increases to 5.85 . Similarly, reducing the share of bondholders (from 20\% to 15\%) and increasing the shares of workers correspondingly, increases the premium to 5.65 . The main channel works through the broader application of the wage contract, which tends to increase both the volatility of the returns to capital and shareholders consumption. This mechanism also dominates if we assume that the wage received by bondholders and shareholders is equal to the contract wage instead of the spot wage (equal to marginal productivity of labor). On the other hand, dropping the contract wage entirely and replacing it with the spot wage for all agents, reduces the risk premiums back to the representative agent case $(E P=0.80)$ as it implies a constant wage share over the cycle. Liquidity constrained workers as such do not explain high risk premiums.

\section{Decomposition of the risk premium for equity and bond returns}

In the baseline model, the risk premium is significantly higher for equity than for bonds ( 5.18 for equity versus 2.34 for the excess holding period return on the 10 year bond). This difference is explained by the difference in the payout risk of both assets. In order to illustrate this, it is helpful to decompose the risk premium related to any future income stream $\left(d_{t+k}\right)$ in its two components: the covariance between the expected stochastic discount factor (SDF) and the marginal utility of the shareholder on the one hand, and the covariance between the future income stream and the marginal utility on the other (see Jermann, 1998 for a more detailed discussion of this decomposition).

$$
R P\left(d_{t+k}\right)=-\operatorname{cov}\left(E_{t+1} \lambda_{t+k}-\lambda_{t+1}, \lambda_{t+1}\right)-\operatorname{cov}\left(E_{t+1} d_{t+k}, \lambda_{t+1}\right)
$$

The returns on bond and equity investments can be written as weighted sums of their future income streams, and their risk premium can also be expressed as weighted averages of the corresponding covariance terms. The contribution of the first covariance term is common to stocks and bonds and so any difference in their premiums has to be explained by differences in the payout risk. For equity the payout risk is determined by the uncertainty in the dividend stream. For a bond, the payout uncertainty is zero. ${ }^{20}$

Fig. 2 provides more detail on the different components of the risk premium in the baseline model. The left-hand panel displays the two covariance terms that appear in the formula above, for the dividend stream at different horizons (expressed in quarters). The stochastic discount factor component increases smoothly with the horizon, while the payout premium falls for flows further in the future, reflecting the profile in the response of the dividend stream to the shocks. The

\footnotetext{
${ }^{20}$ In the working paper version of this paper, De Graeve et al. (2008), we also consider inflation and differentiate between nominal and real bonds. In that case, inflation generates payout uncertainty for nominal bonds.
} 

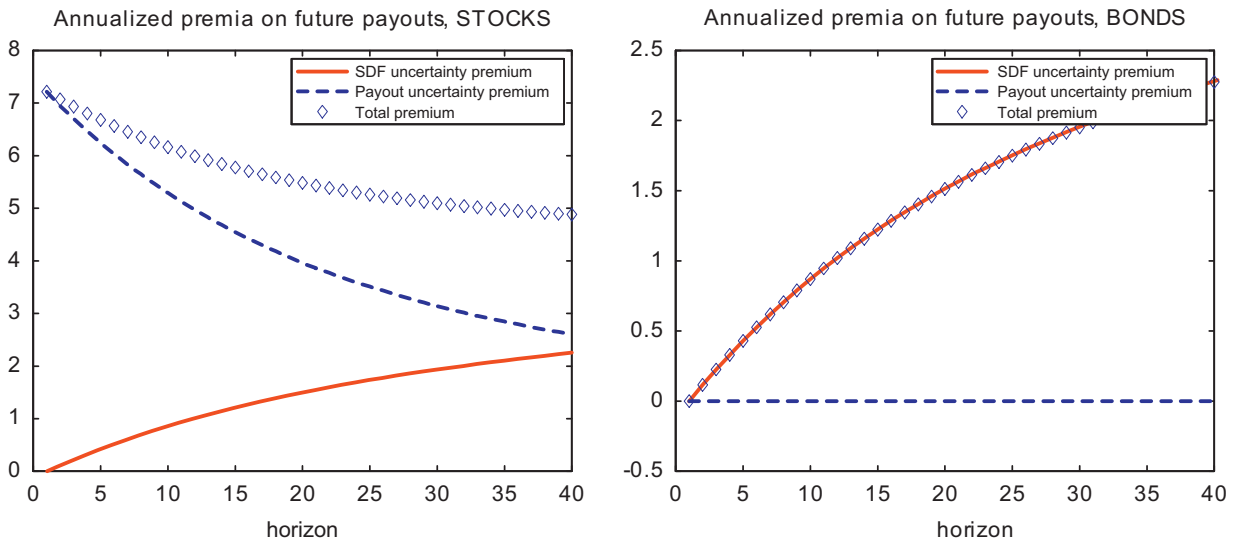

Fig. 2. Decomposition of the risk premium on equity and bonds.

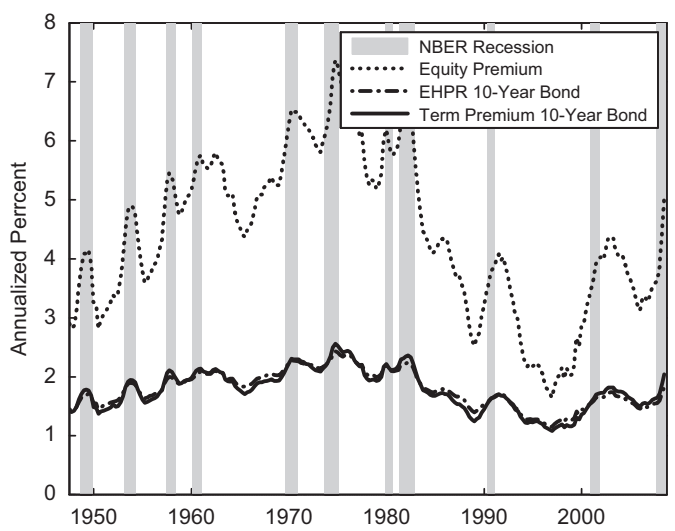

Fig. 3. Time-varying risk premiums. Note: The graph shows model implied expected one period returns for stocks, nominal and real bonds (10 year maturity). The term premium $=y_{t}^{40}-y_{t}^{40^{*}}$, where $y_{t}^{40^{*}}$ is the risk neutral yield. The premiums are expressed in annualized percentages, i.e. quarterly model concepts are multiplied by 400 .

payout risk is clearly dominant for the equity premium, which is a weighted average of these covariance terms. The rightpanel of Fig. 2 provides the same information for the bond premium. Here, the SDF uncertainty is the only determinant of the premium for long horizon bonds.

The dividend stream is affected by the operational leverage, which was discussed in the previous sections, and by the financial leverage that results from the debt financing of firms: the outstanding debt is assumed to remain a constant fraction of $30 \%$ of the capital stock. This financial leverage increases the volatility of dividends (after interest payments) and therefore also the risk premium on equity, while leaving the SR unaffected.

\section{Time variation in the risk premium}

For analyzing average risk premiums, a second order approximation to the equilibrium conditions is sufficient. Here, we are interested in time variation in the risk premium of the model, and thus need to use at least one order of approximation higher than a second order approximation. In this section we use a third order approximation to the equilibrium conditions. We then simulate the model with the historical shocks for the productivity and the distribution risk over the period $1947-2009 .^{21}$

Fig. 3 shows the risk premiums generated by the model based on the historical series of productivity and distribution shocks, along with NBER recessions. Table 14 measures the comovement of the various (expected and realized) premiums with the business cycle as well as their volatilities. Differences in statistics relative to the earlier calibration results arise for two main reasons: first, the present results are based on a higher (third) order approximation. Second, the results here are model outcomes based on the estimated historical shocks.

\footnotetext{
${ }^{21}$ We here use the estimated covariance structure of the shocks without rescaling in order to avoid any inconsistency between the covariance parameters and the actual shock series.
} 
Table 14

Time-varying risk premiums.

\begin{tabular}{llr}
\hline Measure of premium & & Unconditional std. dev. \\
\hline Equity (excess, expected) & $E_{t}\left(R_{t+1}^{S}-R_{t}^{f}\right)$ & 1.36 \\
Equity (excess, realized) & $R_{t+1}^{S}-R_{t}^{f}$ & 25.87 \\
Bond (excess, expected) & $E_{t}\left(h p r_{t+1}\right)$ & 0.31 \\
Bond (excess, realized) & $h p r_{t+1}$ & 8.89 \\
Term Premium & $y_{t}^{40}-y_{t}^{40^{*}}$ & 0.85 \\
Slope Yield Curve & $y_{t}^{40}-R_{t}^{f}$ & -0.82 \\
\hline
\end{tabular}
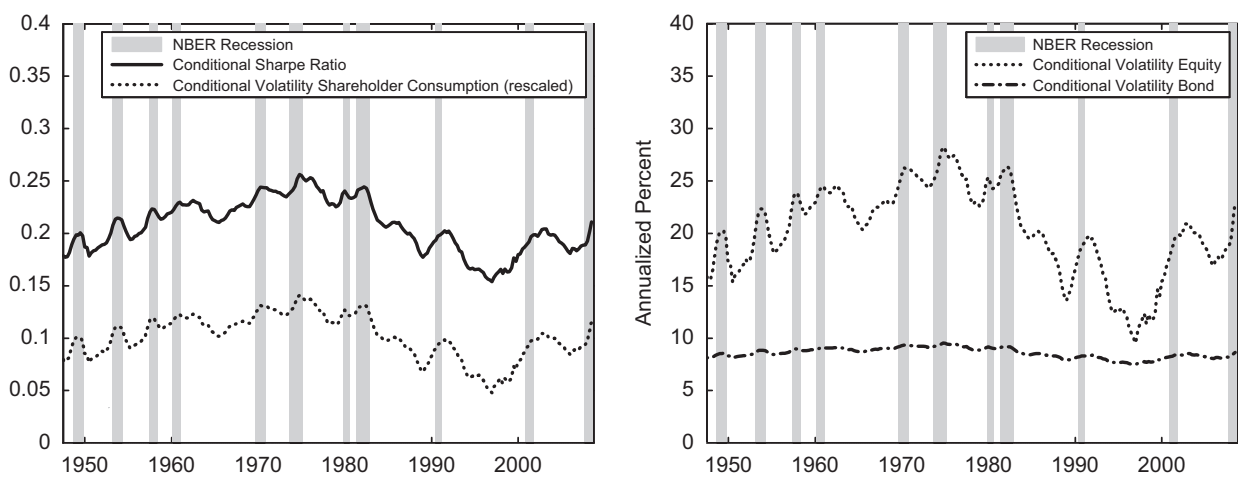

Fig. 4. Conditional volatilities.

Fig. 3 illustrates that the model generates quite some time variation in the equity and bond premium. There is no immediate counterpart in the data for these expected return series and related conditional moments. We compare our results to a number of proxies and results of contemporary models. For equity, Brav et al. (2003) and Söderlind (2009) analyze variations in ex ante measures of expected returns, based on analyst survey and options data. The former obtain an average expected return $E_{t}\left(R_{t+1}^{S}\right)$ of around $20 \%$ for the period 1975-2001. Söderlind's survey data suggest an average expected excess return $E_{t}\left(R_{t+1}^{S}-R_{t}^{f}\right)$ of about $3.25 \%$ while the conditional volatility of returns $\sigma_{t}\left(R_{t+1}^{S}\right)$ is around $16 \%$. The average of the model expected risk premium in Fig. 3 is close to that of Söderlind. The conditional standard deviation of the stock return $\sigma_{t}\left(R_{t+1}^{S}\right)$ in the model, plotted in Fig. 4 (right-hand panel), is slightly above $20 \%$ on average.

For bonds, the model produces an expected holding period return on nominal 10 year bonds of 1.79 (Fig. 3 ). The degree of time variation in expected excess bond returns on bonds is limited (Table 14). Again, there are no immediate measures in the data to compare these to. Relative to estimated models such as Duffee (2002), Dewachter (2008) and Campbell et al. (2008) the magnitude of fluctuations in expected returns is small. By contrast, realized return average and volatility are substantial in the model and compare well to-observable-measures of, e.g., Rudebusch and Swanson (2009) and Campbell et al. (2008). For instance, in Fig. 3 and Table 14 (row 5) we measure the term premium by the difference in yield between the 10 year bond and its risk neutral counterpart (as in Rudebusch and Swanson, 2009). We find that in the present model, this measure for the term premium is high on average (1.78), and substantially volatile (0.34). These numbers establish that models with heterogeneous agents have the ability to resolve the bond premium puzzle (Rudebusch and Swanson, 2008), in addition to the equity premium puzzle. Remark that the model can simultaneously account for the two puzzles.

We now turn to the cyclical properties of these risk premiums. First of all, historically, the patterns of time variation in the ex ante equity return survey measures of Söderlind (2009) and Brav et al. (2003) look very similar to that of Fig. 3. The dynamics of the term premium, too, share the general time-series profile detected in other studies of the term premium: a downward trend in risk premiums during the eighties and nineties. Different from most estimates of the term premium (as summarized in Rudebusch et al., 2007), which continue to fall throughout the early 2000s, the model term premium exhibits an upward pattern starting in the late nineties. ${ }^{22}$ For conditional stock return volatility, the model measure bears close resemblance to the implied option volatility calculated in Söderlind (2009), with similar swings over the entire 19852007 period.

Second, expected returns are strongly countercyclical: the correlation of each of them with linearly detrended output is around -0.8 to -0.9 (Table 14). Fig. 3 shows how model risk premiums increase at the onset of recession periods.

Third, realized returns do not share that same strong countercyclical pattern. For instance, realized stock returns are procyclical, as output gains translate into larger dividends/returns.

\footnotetext{
${ }^{22}$ Remark that this comparison is based on a real concept in the model, and a nominal one in the data.
} 
It is useful to try to understand the time variability of expected returns in the model a bit further. We know from the results in Section 5 that, on average, payout risk is the largest contributor to the equity premium. The bond premium is solely driven by SDF uncertainty, and is therefore substantially smaller. Similarly, time variability in risk premiums can work through two channels: the risk premium is the product of the price and the amount of risk, both of which can vary through time. Below, we provide variations in the different components of the risk premiums.

First, there is the time variation in the compensation for risk that the shareholders expect in return for bearing part of the aggregate risk. This corresponds to time variation in the price of risk, which is summarized in the Sharpe ratio. The Sharpe ratio itself is a function of the volatility of marginal utility, as well as its comovement with the asset's payoff. In the present model, the shareholders' effective risk aversion is virtually constant. The reason is that the shareholders are extremely wealthy (see the wealth distribution of the three agents). As a result, time variation in the Sharpe ratio is fully driven by variation in the conditional volatility of consumption. ${ }^{23}$ Fig. 4 (left-hand panel) shows this conditional volatility of shareholder consumption growth and, in particular, its countercyclical nature. All risk premiums share this component. Hence, variation in consumption growth volatility is the driving force between the comovement of the various risk premiums of Fig. 3.

Second, there is time variation in the amount of aggregate risk the shareholders bear across the cycle. The latter is summarized in the expected variability of the returns. Here lies the main explanation for the time variation and the overall magnitudes of risk premiums, as well as the relative differences in them between stocks and bonds. The right-hand panel of Fig. 4 shows the conditional volatilities for the various assets in our model economy. Clearly, the return volatility for stocks varies substantially over the business cycle. For bonds, this is much less the case.

In sum, the time variation in risk premiums stems from variation in both return and shareholder consumption volatility. The obvious next question is: where does it come from? First of all, as with the average risk premiums, the main source lies in the worker-shareholder interaction. Although the Guvenen mechanism is at work (where bondholders' demand for insurance is higher in recessions, and thereby the volatility of shareholder consumption), it is quantitatively negligible. What matters is that operational and financial leverage make profits and in particular dividends much more volatile in recessions. The volatile dividends translate into more volatile returns. Financial leverage, however, does not affect shareholders' income and thus cannot explain the surges in shareholder consumption volatility observed in recessions in Fig. 4. The cause of increased volatility in shareholder income is operational leverage. Operational leverage implies a wage share that is countercyclical. Just as the shareholder is at his lowest wealth level, the volatility of profits will reach its highest level.

Interestingly, even though the model does not receive any financial market data as inputs, it associates the current crisis with substantial financial volatility. In particular, the final quarter of 2008 marks the single most dramatic increase in the price of risk in our sample: the conditional Sharpe ratio increases by more than 5\% (and 2009q1 a close second with a rise of $4.3 \%$ ). The equity and bond risk premiums also record unseen single-quarter jumps at over 60 and $10 \mathrm{bp}$, respectively. In cumulative terms, the equity risk premium has gone up by 163bp during the current slowdown, while the bond premium has increased with $31 \mathrm{bp}$.

The documented countercyclical behavior of risk premiums is consistent with both theory and evidence in the finance literature. Risk averse investors should require high returns when their marginal utility of consumption is high. ${ }^{24}$

\section{Conclusions}

The objective of this paper was to build a DSGE model that is able to fit well both on the real and the financial side of the economy. The results illustrate that a heterogeneous agent model can be a useful alternative to the standard representative agent model for modeling jointly the real and the financial side of the economy. Starting from a realistic classification of households in three groups, portfolio investors, bondholders and workers who differ from each other in terms of capital market participation and risk aversion, our model generates high risk premiums and reasonable dynamics for the intraand intertemporal allocation decisions. The model also generates a significant degree of countercyclical time variation in the risk premiums. There are two important ingredients for generating the high risk premiums. Firstly, the concentration of consumption risk in the group of shareholders results in high prices of risk. Secondly, the labor contract and the presence of distribution risk result in a high volatility of capital returns. The bond market, that allows for a redistribution of risk between bond- and shareholders, has a relatively minor impact on the results.

For future work, it would also be interesting to complete the stochastic structure of the model and to estimate the complete model, augmented with sticky prices and a monetary policy rule, on the data. Recent progress in higher order estimation methods suggests that such an exercise will become feasible soon. However, a complete higher order approximation of the model is probably not required given the limited magnitude of the feedback effects from risk premiums towards the real economy. In order to increase these feedback effects, one could consider a model switching framework, in which the parameters of the model, and in particular the risk aversion, can also change in line with the

\footnotetext{
${ }^{23}$ For the heterogeneous agent model with GHH preferences, the labor effect is quantitatively not very important

24 Predictive regressions, for instance, also suggest expected returns are high in "bad" times. In De Graeve et al. (2010), we document the performance of the model in this respect.
} 
stochastic risks that hit the economy. Alternatively, one could add financial frictions to the model so that the required risk premiums have first order effects on consumption and investment decisions. A joint fit of the financial and the real data will imply a more exact validation test for the model. It remains to be seen how the heterogeneous agent setting performs in explaining the real variables relative to the representative agent models which are now standard in New-Keynesian monetary models (e.g., Smets and Wouters, 2007). In that respect, it is important to stress that the model is able to generate endogenously the observed real wage rigidity as the result of an efficient risk sharing arrangement between workers and firms. This view on wage rigidity was popular in the late seventies, and recently regained support from micro studies on wage dynamics and their reaction to transitory firm-specific shocks (Guiso et al., 2005).

\section{Acknowledgments}

We would like to thank Willi Semmler, two anonymous referees, our discussants Gianni Amisano, Michel Juillard, Christos Koulovatianos and Xavier Ragot, as well as participants at the conferences on Computing in Economics and Finance (University Paris-Sorbonne), "Towards an Integrated Macro-Finance Framework for Monetary Policy Analysis" (National Bank of Belgium), "New Developments in DSGE Models" (University of Nottingham), "Theories and Methods in Macroeconomics" (BETA, Université de Strasbourg) and seminars at the Bundesbank, Erasmus University Rotterdam, European Central Bank and Ghent University. The views expressed herein are solely the responsibility of the authors and should not be interpreted as reflecting the views of the Executive Board of Sveriges Riksbank, Bank of Canada, or the National Bank of Belgium.

\section{References}

Benigno, P., 2009. Price stability with imperfect financial integration. Journal of Money, Credit and Banking 41, $121-149$.

Boldrin, M., Horvath, M., 1995. Labor contracts and business cycles. Journal of Political Economy 103, 972-1004.

Boldrin, M., Christiano, L., Fisher, J., 2001. Habit persistence, asset returns and the business cycle. American Economic Review 91, $149-166$.

Brav, A., Lehavy, R., Michaely, R., 2003. Using expectations to test asset pricing models. Financial Management 34, 31-64.

Campbell, J.Y., Sunderam, A., Viceira, L.M., 2008. Inflation bets or deflation hedges? The Changing Risks of Nominal Bonds, manuscript.

Chien, Y.L., Lustig, H.N., Cole, H.L., 2010. A multiplier approach to understanding the macro implications of household finance. Review of Economic Studies, forthcoming.

Danthine, J.-P., Donaldson, J.B., 2002. Labor relations and asset returns. Review of Economic Studies 69, 41-64.

Danthine, J.-P., Donaldson, J.B., Siconolfi, P., 2008. Distribution risk and equity returns. In: Mehra, R. (Ed.), The Handbook of the Equity Risk Premium, North Holland Handbooks of Finance Series. Elsevier, Amsterdam, pp. 415-462.

De Graeve, F., Dossche, M., Emiris, M., Sneessens, H., Wouters, R., 2008. Risk premiums and macroeconomic dynamics in a heterogeneous agent model. National Bank of Belgium Working Paper no. 150.

De Graeve, F., Dossche, M., Emiris, M., Sneessens, H., Wouters, R., 2010. Risk premiums and macroeconomic dynamics in a heterogeneous agent model. Riksbank Working Paper no. 236.

Dewachter, H., 2008. Imperfect information, macroeconomic dynamics and the yield curve: an encompassing macro-finance model. National Bank of Belgium Working Paper no. 144.

Duffee, G.R., 2002. Term premia and interest rate forecasts in affine models. Journal of Finance 57, $405-443$.

Gomme, P., Greenwood, J., 1995. On the cyclical allocation of risk. Journal of Economic Dynamics and Control 19, 91-124.

Greenwood, J., Hercowitz, Z., Huffman, G., 1988. Investment, capacity utilization and the real business cycle. American Economic Review $78,402-417$.

Guiso, L., Pistaferri, L., Schivardi, F., 2005. Insurance within the firm. Journal of Economic Perspectives 11, $1054-1087$.

Guvenen, F., 2009. A parsimonious macroeconomic model for asset pricing. Econometrica 77, 1711-1750.

Jaimovich, N., Rebelo, S., 2009. Can news about the future drive the business cycle? American Economic Review 99, 1097-1118

Jermann, U., 1998. Asset pricing in production economies. Journal of Monetary Economics 41, 257-275.

King, R., Plosser, C., Rebelo, S., 1988. Production, growth and business cycles I: the basic neoclassical growth model. Journal of Monetary Economics 21, 195-232.

Kocherlakota, N., 1996. The equity premium: it's still a puzzle. Journal of Economic Literature 34, 42-71.

Lettau, M., Uhlig, H., 2000. Can habit formation be reconciled with business cycle facts? Review of Economic Dynamics 3, 79-99

Rios-Rull, V., Santaeulalia-Llopis, R., 2008. Redistributive shocks and productivity shocks. Manuscript.

Rudebusch, G.D., Sack, B., Swanson, E.T., 2007. Macroeconomic implications of changes in the term premium. Federal Reserve Bank of St. Louis Review 89, 241-269.

Rudebusch, G.D., Swanson, E.T., 2008. Examining the bond premium puzzle with a DSGE model. Journal of Monetary Economics 55, S111-S126.

Rudebusch, G.D., Swanson, E.T., 2009. The bond premium in a DSGE model with long-run real and nominal risks. Manuscript.

Smets, F., Wouters, R., 2007. Shocks and frictions in US business cycles: a Bayesian DSGE approach. American Economic Review $97,586-606$.

Söderlind, P., 2009. The C-CAPM without ex post data. Journal of Macroeconomics 31, 721-729.

Uhlig, H., 2007. Explaining asset prices with external habits and wage rigidities in a DSGE model. American Economic Review 97, $239-243$.

Vissing-Jørgensen, A., 2002. Limited asset market participation and the elasticity of intertemporal substitution. Journal of Political Economy 110, $825-853$.

Wolff, E.N., 2006. Changes in household wealth in the 1980s and 1990s in the US. In: Wolff, E.N. (Ed.), International Perspectives on Household Wealth. Elgar Publishing Ltd. 